\title{
Allelism of MCKD, FJHN and GCKD caused by impairment of uromodulin export dynamics
}

\author{
Luca Rampoldi ${ }^{1}$, Gianluca Caridi ${ }^{2}$, Daniela Santon ${ }^{3}$, Francesca Boaretto ${ }^{3}$, \\ Ilenia Bernascone ${ }^{1}$, Giuseppe Lamorte ${ }^{1}$, Regina Tardanico ${ }^{4}$, Monica Dagnino², \\ Giacomo Colussi ${ }^{5}$, Francesco Scolari ${ }^{4}$, Gian Marco Ghiggeri ${ }^{2}$, \\ Antonio Amoroso ${ }^{3}$ and Giorgio Casari ${ }^{1, *}$
}

\begin{abstract}
${ }^{1}$ DIBIT, San Raffaele Scientific Institute, 20132, Milan, Italy, ${ }^{2}$ Laboratory on Pathophysiology of Uremia, G. Gaslini Institute, 16148, Genoa, Italy, ${ }^{3}$ Genetics Service, Istituto per I'Infanzia Burlo Garofolo, 34137, Trieste, Italy, ${ }^{4}$ Spedali Civili and University of Brescia, 25123, Brescia, Italy and ${ }^{5}$ Unita' di Nefrologia, Ospedale di Circolo, 21100, Varese, Italy
\end{abstract}

Received August 28, 2003; Revised and Accepted October 14, 2003

The disease complex medullary cystic disease/familial juvenile hyperuricemic nephropathy (MCKD/FJHN) is characterized by alteration of urinary concentrating ability, frequent hyperuricemia, tubulo-interstitial fibrosis, cysts at the cortico-medullary junction and renal failure. MCKD/FJHN is caused by mutations of the gene encoding uromodulin, the most abundant protein in urine. Here, we describe new missense mutations in three families with MCKD/FJHN and demonstrate allelism with a glomerulocystic kidney disease (GCKD) variant, showing association of cyst dilatation and collapse of glomeruli with some clinical features similar to MCKD/FJHN as hyperuricemia and impairment of urine concentrating ability. Furthermore, we provide the first functional characterization of uromodulin mutations. The four newly identified mutants were characterized by immunofluorescence and FACS analysis on transfected cells. These experiments showed that all uromodulin mutations cause a delay in protein export to the plasma membrane due to a longer retention time in the endoplasmic reticulum. Immunohistochemistry on GCKD and MCKD/FJHN kidney biopsies revealed dense intracellular accumulation of uromodulin in tubular epithelia of the thick ascending limb of Henle's loop. Electron microscopy demonstrated accumulation of dense fibrillar material within the endoplasmic reticulum. Consistently, patient urines show a severe reduction of excreted uromodulin. The maturation impairment is consistent with the clinical findings and suggests a pathogenetic mechanism leading to these kidney diseases.

\section{INTRODUCTION}

Glomerulocystic kidney disease (GCKD) and medullary cystic disease/familial juvenile hyperuricemic nephropathy (MCKD/ FJHN) are two distinct renal disorders that share some common clinical features. The former is characterized by a cystic dilatation of Bowman's space and a collapse of glomerular tuft. Familial GCKD can be associated with either hypoplastic or normal sized kidneys. A GCKD clinical variant presents the association with hyperuricemia due to low fractional excretion of uric acid and severe impairment of urine concentrating ability that are reminiscent of MCKD/FJHN (1).
MCKD is a typical tubulo-interstitial disorder characterized by alteration of urinary concentration, frequent hyperuricemia, tubulo-interstitial fibrosis, frequent cysts at the corticomedullary junction and renal failure. It is a genetic and clinical heterogeneous disorder with two known loci on chromosome 1q21 (MCKD1; MIM 174000) (2) and on chromosome $16 \mathrm{p} 12$ (MCKD2; MIM 603860) (3). FJHN (MIM 162000) features are very similar to those seen in MCKD, that is hyperuricemia, gout, progressive renal failure at an early age, and autosomaldominant inheritance. Common critical regions (4-7) raised the possibility that MCKD and FJHN could arise from mutations of the same gene. In fact, both diseases were found associated

*To whom correspondence should be addressed at: Human Molecular Genetics Unit, DIBIT-San Raffaele Scientific Institute, Via Olgettina 58, 20132 Milan, Italy. Tel: +39 0226433502; Fax: +39 0226434767; Email: casari.giorgio@hsr.it 
to uromodulin mutations $(8,9)$. Uromodulin, also referred to as Tamm-Horsfall protein, is exclusively expressed by epithelial cells of the thick ascending limb (TAL) of the loop of Henle (10) and by distal convoluted tubules (DCT) (11) and is the most abundant protein in urine. Uromodulin was initially characterized by Tamm and Horsfall in 1950 (12), but despite being extensively studied in the past 50 years its function is not well established. It has been hypothesized to be responsible for water impermeability of the TAL due to its ability to form a reversible gel-like structure $(13,14)$ and to modulate the urothelial defense against infections (15). These putative functions seem directly correlated with the typical clinical manifestations of MCKD/FJHN that are alterations of concentrating ability and tubulo-interstitial infiltration and fibrosis.

Here we describe new mutations of uromodulin in three Italian families with MCKD/FJHN and the first reported uromodulin mutation in a GCKD family. Immunohistochemistry and electron microscopy on patient kidney biopsy reveal pathologic evidence of dense intracellular accumulation of this protein in tubular epithelia of the thick ascending limb of Henle's loop. Consistently, the amount of excreted uromodulin is severely reduced in patients' urine. Cellular studies with uromodulin mutants demonstrate impairment of maturation/export dynamics, thus defining the pathogenetic mechanism leading to these kidney diseases.

\section{RESULTS}

\section{Clinical findings}

In this study we performed clinical and genetic analysis of individuals from three MCKD/FJHN and one GCKD Italian families (Fig. 1). Clinical features of family MCKD\#1 have been already described (3). The GCKD\#1 family included three affected patients in two generations (1). Patients III-2 and III-3 were two siblings of 40 and 41 years with mild renal insufficiency and normal or mild polyuria. Both had an increase of serum uric acid and decreased urine osmolality. The youngest member (IV-1) was a male of 16 years with hyperuricemia, slight increase of serum creatinine and defective urine osmolality. In order to exclude GCKD associated with maturity-onset diabetes, we performed glucose tolerance test and HNF-1 $\beta$ (16) sequence analysis, both resulting negative. Ultrasound evaluations in all patients demonstrated reduced kidney volumes with cortical hyperechogenicity. Renal tissue was available in III-2 and III-3 showing, in both cases, marked dilatation of Bowman's space in most glomeruli (about $40 \%$ ) with reduced or rudimentary glomerular tufts attached to the capsule. No tubular dilatations and/or dysplastic elements were found. Diffuse albeit mild interstitial fibrosis was present. Family MCKD\#7 included 47 members, 17 of which presented at least one symptom characteristic of the disease. All but one (V-2) had reduced urine osmolality and polyuria. At the time of examination, seven patients (III-4, III-5, III-12, III-13, III-16, IV-2, IV-15) presented an association of chronic renal failure (CRF) and hyperuricemia with or without gout, while hyperuricemia was isolated in four cases (III-2, III-3, III-19, IV-6) and CRF was the unique symptom in 4 (III-7, IV-3, IV-11, V-1). In one patient (V-2) the unique finding was the presence of numerous renal cysts and finally low urine osmolality was the only finding in one patient (IV-17). The three-generation Italian pedigree MCKD\#9 included five affected individuals. Three members (II-2, III-1 and III-2) were available for clinical and genetic analysis. Individual II-2 had polyuria and nycturia since infancy and increased serum creatinine and uric acid levels since age 17. Her mother (I-2) died from severe renal failure. At the moment of diagnosis the proband creatinine serum level was $2.6 \mathrm{mg} / \mathrm{dl}$ and serum uric acid level was between 8.7 and $9.3 \mathrm{mg} / \mathrm{dl}$. Kidneys were small, without cysts, and with rounded calices at urography analysis. Proteinuria was absent and urine sediment analysis was negative. Renal function was progressively impaired and presently at the age of 60 the patient has started to undergo dialysis treatment. She experienced gouty attacks that were successfully treated with Allopurinol. Individuals III-1 and III-2 are respectively 17 and 21 years old. They show elevated serum creatinine and uric acid levels with absence of proteinuria and pathologic sediment. They both have nycturia and small kidneys without cysts.

The main clinical findings of the $28 \mathrm{MCKD} / \mathrm{FJHN}$ and three GCKD patients are shown in Table 1. Despite a remarkable inter- and intra-familial variability, two clinical signs seem to be shared by the vast majority of patients. Impairment of urine concentrating ability, with urine osmolality lower than 800 mOsm (mean urine osmolality was $404.8 \pm 156.8 \mathrm{mOsm}$ ), was evident in all but two of the 31 analyzed patients (family MCKD\#1, individual IV-5; family MCKD\#7, individual V-2). Elevated serum level of uric acid is present in all the MCKD/ FJHN and GCKD patients with the exception of patients IV-11, IV-17, V-1 and V-2 of family MCKD\#7. Considering all affected members, the mean serum uric acid concentration was $8.3 \pm 2.3 \mathrm{mg} / \mathrm{dl}$ whereas it was $3.7 \pm 1 \mathrm{mg} / \mathrm{dl}$ in unaffected relatives. Interestingly, patients from family MCKD\#1 seem to have a milder phenotype. In fact, none of them has developed CRF and one patient only (II-3) has undergone dialysis treatment by the age of 60 .

\section{Mutational analysis}

We performed mutational analysis in the $U M O D$ gene, which encodes uromodulin, in the three MCKD/FJHN and one GCKD families described above. All families were either linked or compatible with linkage to the chromosome $16 \mathrm{p} 12$ MCKD2 locus. Family MCKD\#1 is the original one that we analyzed for the linkage mapping of $M C K D 2$ locus (3). Family MCKD\#7 was significantly linked to the same chromosomal region with $Z_{\max }=3.7 \quad(\theta=0.00)$ for marker D16S3041. Families MCKD\#9 and GCKD\#1 were compatible with linkage to chromosome $16 \mathrm{p} 12$, although not reaching statistically significant LOD score values.

Direct DNA sequencing of $U M O D$ gene revealed four new non-conservative missense mutations (Fig. 2) that are listed in Table 2. We verified cosegregation of the mutations with the disease haplotypes by direct-sequencing all the family members and confirmed a complete penetrance, since no unaffected member carried the disease haplotype and, therefore, $U M O D$ mutation. None of the four missense mutations was found in 200 control chromosomes. 

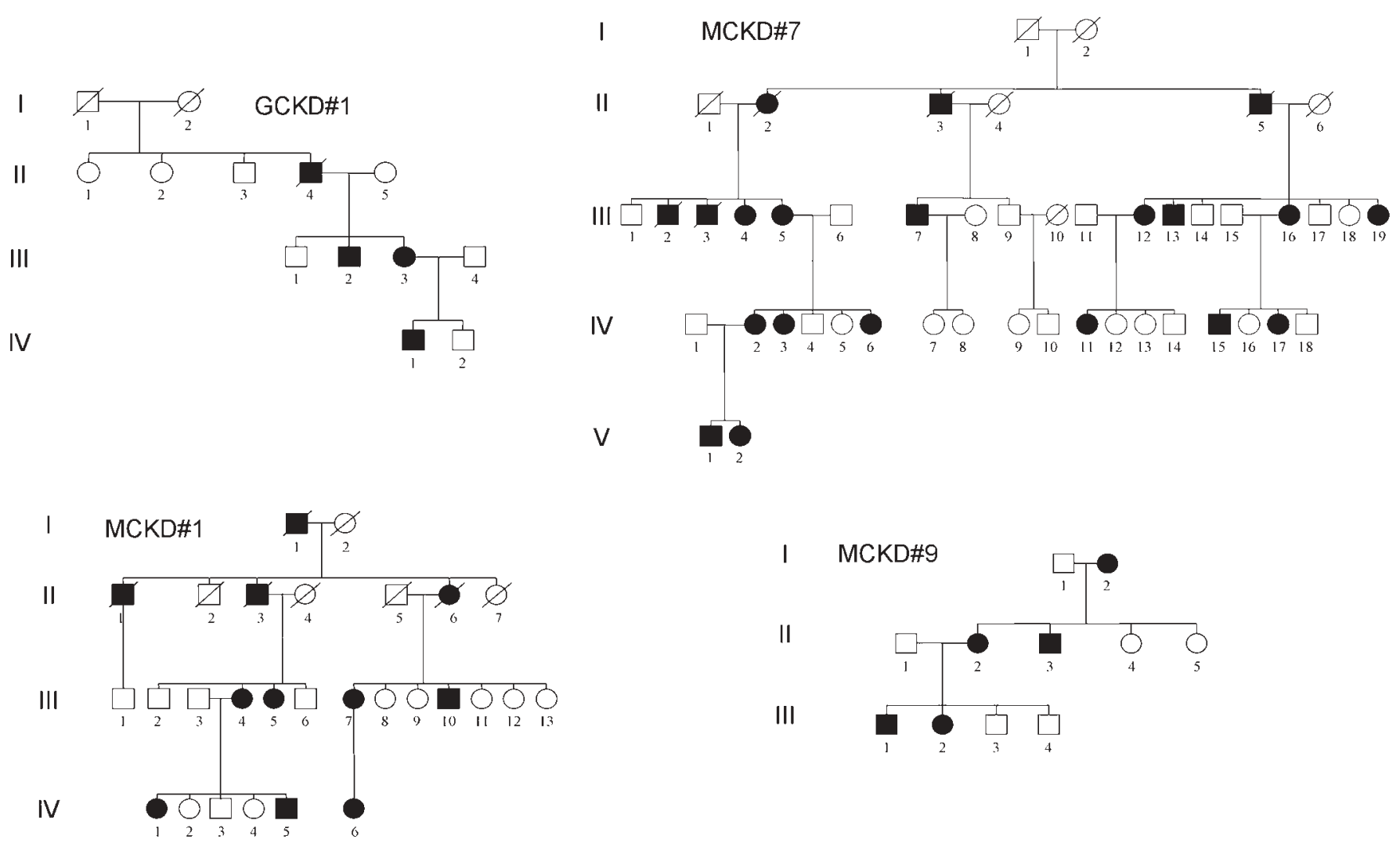

Figure 1. Pedigrees of families MCKD\#1, MCKD\#7, MCKD\#9 and GCKD\#1.

Uromodulin is a very highly conserved protein showing approximately the same degree of sequence similarity $(77-83 \%$ identities) with its rat, mouse, dog and cow homologs (Fig. 3). An important feature is the high content of cysteine residues (48 out of 640 amino acids; $7.5 \%$ ) that are prevalently distributed in the N-terminus. All cysteine residues are conserved in uromodulin mammalian homologs, including C148, C150, C315 and C317 that we found mutated in MCKD/ FJHN and GCKD patients.

Uromodulin secondary and tertiary structure is not well established. The representation shown in Figure 4 was obtained by computer-based analysis with domain/pattern identification programs and is in agreement with previously reported ones (17) with exception of an additional EGF-like domain (IV). Uromodulin mutations $\mathrm{C} 148 \mathrm{~W}, \mathrm{C} 315 \mathrm{R}$ and $\mathrm{C} 317 \mathrm{Y}$ hit cysteine residues that localize in cbEGF-like domains III and IV. Although cysteine residue 150 is not part of any recognizable domain, it is probably engaged in intrachain disulfide bond formation, since the protein monomer does not contain any free sulfydryl group (18).

\section{Delayed export of uromodulin mutant isoforms to the plasma membrane}

Uromodulin is synthesized as an $84 \mathrm{kDa}$ precursor that is slowly converted to the mature glycosylated protein with an apparent molecular weight of $97 \mathrm{kDa}$. The maturation rate appears to be dependent on the retention time in the endoplasmic reticulum (ER) probably because the rate-limiting step is the formation of the correct set of disulfide bonds in that compartment (19).

We hypothesized that the MCKD/FJHN and GCKD mutations could hit cysteine residues involved in disulfide bonds therefore affecting the maturation/export rate of uromodulin. To assess this hypothesis, we performed transient transfection experiments using wild-type and mutant constructs in HEK293 and HeLa cell lines that do not express uromodulin. When transfecting with equal amounts of constructs and with equal transfection efficiency, as determined by cotransfection with an EGFP-expressing plasmid, we were able to reveal significant differences in cells transfected with mutant constructs compared with wild-type ones.

Four hours after transfection the amount of uromodulin that was exposed on the plasma membrane was significantly reduced in cells expressing the mutant constructs. This was evident in immunofluorescence experiments as a marked reduction of both the number of positive cells and the intensity of uromodulin staining (Fig. 5). Interestingly, cells expressing wild-type uromodulin that were cultured in reducing conditions showed a marked reduction of membrane-exposed uromodulin, mimicking the mutant phenotype (data not shown).

In order to better define the uromodulin export dynamics, we performed time-lapse experiments by fixing cells at different times after transfection $(2,4,6,8,12,20,40,48,50$ and $74 \mathrm{~h})$. The reduction of the amount of mutant uromodulin signal on the plasma membrane could be clearly seen up to $8-12 \mathrm{~h}$ after 
Table 1. Clinical and molecular findings in the reported MCKD/FJHN and GCKD families

\begin{tabular}{|c|c|c|c|c|c|c|c|c|}
\hline Family & Patient & $\begin{array}{c}\text { Age at } \\
\text { diagnosis }\end{array}$ & $\begin{array}{l}\text { Morning urinary } \\
\text { osmolality } \\
\left(\mathrm{mOsm} \mathrm{H}_{2} \mathrm{O} / \mathrm{kg}\right)\end{array}$ & $\begin{array}{l}\text { Serum } \\
\text { creatinine } \\
(\mathrm{mg} / \mathrm{dl})\end{array}$ & $\begin{array}{l}\text { Serum } \\
\text { uric acid } \\
(\mathrm{mg} / \mathrm{dl})\end{array}$ & Gout & $\begin{array}{c}\text { Renal } \\
\text { ultrasound }\end{array}$ & $\begin{array}{c}\text { Uromodulin } \\
\text { change }\end{array}$ \\
\hline ADMCKD\#1 & II-3 & 54 & 300 & 2 & 12 & $\mathrm{y}$ & $\mathrm{SK}, \mathrm{MC}$ & $\mathrm{C} 317 \mathrm{Y}$ \\
\hline ADMCKD\#1 & III-4 & 18 & 300 & 1.5 & 9.6 & $\mathrm{n}$ & SK & C317Y \\
\hline ADMCKD\#1 & III-5 & 25 & 330 & 1.6 & 5.9 & $\mathrm{n}$ & SK & C317Y \\
\hline ADMCKD\#1 & III-7 & 30 & 315 & 1.3 & 9.2 & $\mathrm{n}$ & SK & C317Y \\
\hline ADMCKD\#1 & III-10 & 29 & 295 & 1.7 & 12 & $\mathrm{y}$ & $\mathrm{SK}$ & C317Y \\
\hline ADMCKD\#1 & IV-1 & 16 & 310 & 1.6 & 5.5 & $\mathrm{n}$ & $\mathrm{SK}$ & C317Y \\
\hline ADMCKD\#1 & IV-5 & 17 & 900 & 0.8 & 7.5 & $\mathrm{n}$ & NK & C317Y \\
\hline ADMCKD\#1 & IV-6 & 18 & 330 & 1.5 & 9.5 & $\mathrm{n}$ & NK & C317Y \\
\hline ADMCKD\#7 & III-2 & 50 & nd & 0.8 & 8 & $\mathrm{y}$ & nd & C150S \\
\hline ADMCKD\#7 & III-3 & 55 & nd & 0.9 & 9 & $\mathrm{y}$ & NK & C150S \\
\hline ADMCKD\#7 & III-4 & 60 & nd & 6 & 10 & $\mathrm{y}$ & $\mathrm{SK}$ & C150S \\
\hline ADMCKD\#7 & III-5 & 60 & nd & 8 & 10 & $\mathrm{y}$ & SK & C150S \\
\hline ADMCKD\#7 & III-7 & 65 & nd & 2.8 & 7.1 & $\mathrm{n}$ & SK & C150S \\
\hline ADMCKD\#7 & III-12 & 50 & 300 & 10 & 11 & $\mathrm{y}$ & SK & C150S \\
\hline ADMCKD\#7 & III-13 & 60 & 320 & 2.5 & 12 & $\mathrm{y}$ & SK & C150S \\
\hline ADMCKD\#7 & III-16 & 65 & 400 & 1.7 & 8 & $\mathrm{y}$ & SK & C150S \\
\hline ADMCKD\#7 & III-19 & 67 & nd & 0.8 & 9 & $\mathrm{y}$ & NK & nd \\
\hline ADMCKD\#7 & IV-2 & 40 & 408 & 2.5 & 11 & $\mathrm{y}$ & $\mathrm{SK}$ & C150S \\
\hline ADMCKD\#7 & IV-3 & 45 & 350 & 9 & 7 & $\mathrm{n}$ & SK & C150S \\
\hline ADMCKD\#7 & IV-6 & 40 & 575 & 0.6 & 7.4 & $\mathrm{y}$ & NK & C150S \\
\hline ADMCKD\#7 & IV-11 & 25 & 650 & 1.6 & 5 & $\mathrm{n}$ & $\mathrm{NK}, \mathrm{MC}$ & C150S \\
\hline ADMCKD\#7 & IV-15 & 40 & 390 & 1.5 & 8 & $\mathrm{y}$ & $\mathrm{NK}, \mathrm{MC}$ & C150S \\
\hline ADMCKD\#7 & IV-17 & 42 & 729 & 0.9 & 4.6 & $\mathrm{n}$ & NK & C150S \\
\hline ADMCKD\#7 & $\mathrm{V}-1$ & 21 & 410 & 1.4 & 3 & $\mathrm{n}$ & $\mathrm{NK}, \mathrm{MC}$ & C150S \\
\hline ADMCKD\#7 & $\mathrm{V}-2$ & 28 & 912 & 0.4 & 3.5 & $\mathrm{n}$ & $\mathrm{NK}, \mathrm{MC}$ & C150S \\
\hline ADMCKD\#9 & II-2 & 39 & 308 & 2.6 & 9.2 & $\mathrm{y}$ & SK & C148W \\
\hline ADMCKD\#9 & III-1 & 17 & 319 & 1.9 & 8.9 & $\mathrm{n}$ & SK & C148W \\
\hline ADMCKD\#9 & III-2 & 21 & 364 & 2.1 & 8.6 & $\mathrm{n}$ & SK & C148W \\
\hline GCKD\#1 & III-2 & 12 & 420 & 2.3 & 8 & $\mathrm{n}$ & $\mathrm{SK}, \mathrm{CC}$ & C315R \\
\hline GCKD\#1 & III-3 & 11 & 380 & 1.8 & 9 & $\mathrm{n}$ & $\mathrm{SK}, \mathrm{CC}$ & $\mathrm{C} 315 \mathrm{R}$ \\
\hline GCKD\#1 & IV-1 & 9 & 300 & 1.3 & 8.5 & $\mathrm{n}$ & $\mathrm{NK}, \mathrm{CC}$ & C315R \\
\hline
\end{tabular}

SK, small kidneys; NK, normal kidneys; MC, medullary cysts; CC, cortical cysts; nd, not determined.

transfection, while it was more difficult to be detected at longer times. Eventually, mutant cells were similar to wild-type ones by $48 \mathrm{~h}$ after transfection.

We verified that the lower amount of exposed mutant uromodulin was not due to an overall reduction of protein amount in the cell due to reduced transcription/translation efficiency of the mutant constructs. Western blot analysis showed a comparable uromodulin signal in mutant and wildtype transfected cells (data not shown).

Different amounts of exposed uromodulin between wild-type and mutant expressing cells were confirmed by transfections in HeLa cell line. In this system, the difference between mutants and wild-type appeared later than in HEK293, i.e. 6-8 h after transfection. This possibly reflects a difference in the ability of maturating uromodulin in the two cell types.

Interestingly, we observed a dramatic change of cell morphology dependent on uromodulin expression. Both cell types developed several membrane projections that could be seen both in wild-type and mutant transfected cells. The membrane projections seemed to be proportional to the amount of exposed protein and are probably an effect of the increasing amount of uromodulin that is transferred to the plasma membrane (Fig. 6).

In order to quantify the number of transfected cells exposing uromodulin on the plasma membrane we used fluorescent activated cell sorter (FACS) analysis. In HEK293 cells that were sorted $14 \mathrm{~h}$ after transfection a significant difference could be seen. When transfecting with mutant isoforms, the number of uromodulin positive cells was significantly reduced in mutants C148W, C150S and C315R. The extent of the reduction varied in the different mutants and ranged from $40 \%$ in $\mathrm{C} 148 \mathrm{~W}$ and $\mathrm{C} 315 \mathrm{R}$ mutants to $60 \%$ in $\mathrm{C} 150 \mathrm{~S}$ mutant. On the contrary, $\mathrm{C} 317 \mathrm{Y}$ isoform showed values that did not significantly differ from the wild-type (Fig. 7A and B). When simulating the heterozygote state, the number of uromodulin-positive cells was between that of wild-type and mutant. Wild-type transfected cells that were cultured in increasing amounts of DTT showed a progressive reduction of the number of uromodulin-positive cells. To further investigate export dynamics of uromodulin mutants, we sorted cells at 6,8 and $10 \mathrm{~h}$ after transfection. Interestingly, the number of uromodulin-positive cells transfected with $\mathrm{C} 317 \mathrm{Y}$ construct was considerably reduced at $6 \mathrm{~h}$ after transfection and reached values comparable to the wildtype by $10 \mathrm{~h}$ (Fig. 7C).

These results confirm the immunofluorescence findings showing that the four missense mutations found in MCKD/ FJHN and GCKD patients and affecting cysteines 148, 150, 315 and 317 cause a delay in uromodulin export to the plasma membrane. Also, $\mathrm{C} 317 \mathrm{Y}$ mutation affects export kinetics to a lower extent with respect to the other cysteine replacements, 


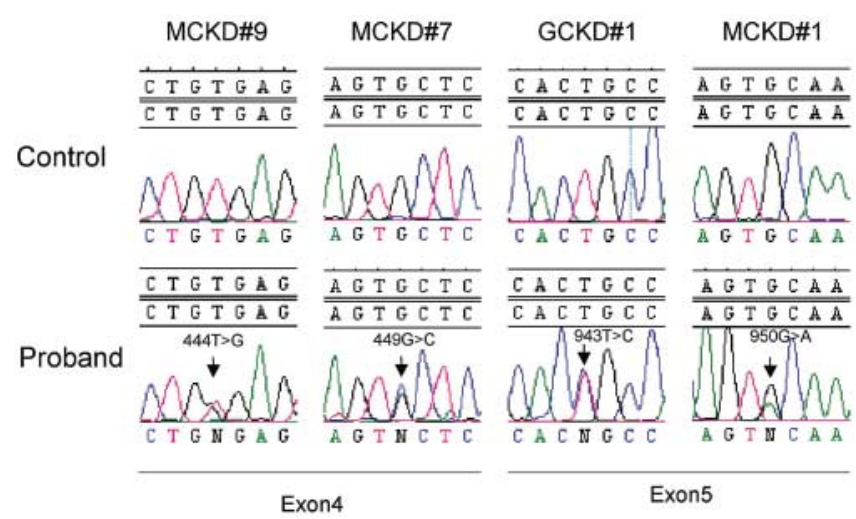

Figure 2. Mutations in the $U M O D$ gene. Top, control subject; bottom, sequences from probands of each family. Affected individuals of family MCKD\#9 are heterozygous for the missense mutation C148W (444T>G); C150S (449G $>$ C) in family MCKD\#7; C315R (943T $>$ C) in family GCKD\#1; C317Y (950G >A) in family MCKD\#1.

showing an initial delay followed by an apparent recovery of the wild-type export activity at longer time. Interestingly, affected members of family MCKD\#1, carrying the C317Y mutation, seem to have a milder phenotype than patients in the other families. This observation suggests a possible correlation between genotype, cellular phenotype and clinical phenotype.

\section{Mutant uromodulin transit through the ER is delayed}

Since uromodulin mutations C148W, C150S, C315R and C317Y affect disulfide bonds, we hypothesized the delayed export to the plasma membrane to be caused by retention of the protein in the ER due to the inability of the resident chaperones to properly fold it. To test this hypothesis, we looked at the intracellular distribution of wild-type and mutant uromodulin in transfected HEK293 and HeLa cells at different times after transfection.

Interestingly, a difference could be detected at early timelapses after transfection. In particular, at $4-8 \mathrm{~h}$ after transfection, wild-type cells showed a strong punctuate uromodulin signal close to the nucleus that resembled a Golgi-like distribution. On the contrary, mutant uromodulin gave a reticular-like signal that was diffused throughout the cytoplasm (Figs 8 and 9).

Colocalization experiments using Golgi (anti-golgin) and ER (anti-calnexin) markers clearly demonstrated that mutant uromodulin was mainly localized in the ER, whilst most intracellular wild-type uromodulin was localized in the Golgi compartment. Uromodulin signal in wild-type expressing cells that were cultured in reducing conditions showed an intracellular distribution very similar to that observed in cells expressing the mutant constructs.

The different distribution was less clear by $24 \mathrm{~h}$ after transfection probably reflecting the bias introduced by overexpression of the protein. These experiments demonstrate that uromodulin mutant isoforms show a delayed transit through the ER, probably because of the inability to establish the physiological disulfide bonds.
Table 2. Mutations in $U M O D$ gene

\begin{tabular}{llll}
\hline Family & Exon & DNA change & Protein change \\
\hline MCKD\#1 & 5 & nt950 G $\rightarrow \mathrm{A}$ & C317Y \\
MCKD\#7 & 4 & nt449 $\mathrm{G} \rightarrow \mathrm{C}$ & $\mathrm{C} 150 \mathrm{~S}$ \\
MCKD\#9 & 4 & $\mathrm{nt} 444 \mathrm{~T} \rightarrow \mathrm{G}$ & $\mathrm{C} 148 \mathrm{~W}$ \\
GCKD\#1 & 5 & $\mathrm{nt943} \mathrm{T} \rightarrow \mathrm{C}$ & $\mathrm{C} 315 \mathrm{R}$ \\
\hline
\end{tabular}

${ }^{a}$ Base no. 1 corresponds to the first base of the translation start codon (AC NM003361).

\section{Immunopathology and electron microscopy}

Normal kidneys were strongly positive to anti-uromodulin antibodies at the thick ascending limb of Henle and at the distal convolute (Fig. 10A and B). In both cases, uromodulin was diffused in the cytoplasm with apical reinforce. Luminal cast reactive to anti-uromodulin antibodies were frequently found, while Bowman's space was mostly negative with the exception of a positive small area adherent to Bowman epithelia (not shown). The pattern was markedly different in kidneys of patients carrying uromodulin mutations, including GCKD. In all cases, uromodulin signal was evident in the same tubule segments, but the protein formed globular masses within the cytoplasm (Fig. 10C-E). These intra-cytoplasm heaps were confirmed by electron microscopy as fibrillar material mostly evident in ER with smaller area overrunning mitochondria (Fig. 10F).

\section{Uromodulin urinary excretion is reduced in MCKD patients}

Urinary excretion of uromodulin was determined by western blot analysis in family MCKD\#1 carrying the mutation C317Y (see below). Figure 11 shows that uromodulin was barely detectable in urine of all the affected subjects carrying the C317Y mutation including two young patients (III-4, III-5) who still had a normal renal function. At variance, non-affected subjects of the same pedigree had normal levels. Moreover, analysis of 20 normal urines revealed fairly high levels in all cases (data not shown).

\section{DISCUSSION}

This work demonstrates for the first time allelism between MCKD/FJHN and GCKD due to uromodulin mutations and shows new insights on the pathogenetic role of the mutant proteins. So far, a GCKD variant associated with hypoplastic kidneys and maturity-onset diabetes of the young has been linked to mutations in the gene encoding the hepatocyte nuclear factor (HNF)-1 $\beta$ (16). Also, HNF-1 $\beta$ mutations were recently identified in patients with atypical FJHN, showing renal cysts, renal developmental abnormalities and diabetes (20). The GCKD family we studied differs from those carrying HNF-1 $\beta$ mutations in that it shows association of glomerular cysts with hyperuricemia, severe impairment of urine concentrating capability and no evidence of diabetes (1). In all cases marked aggregates of uromodulin in tubular cells were observed and electron microscopy demonstrated accumulation of dense 


\begin{abstract}
Homo sapiens Canis familiaris Bos taurus Mus musculus Rattus norvegicus

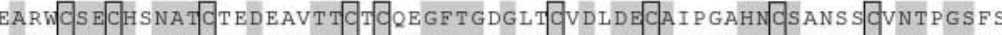

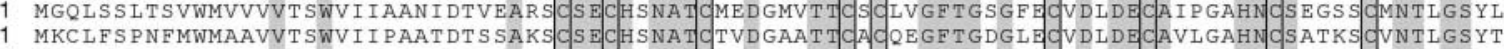

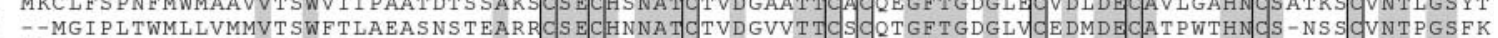
1 MGQLISITWLILVMVVT PWETVAGANDS PEARRCS ECHDNATCVIDGVVTTCSCOAGFTGDGLVIEDIDECATPWTHNDS-NS ICMNTIGSYE Homo sapiens Canis familiaris Bos taurus Mus musculus Rattus norvegicus

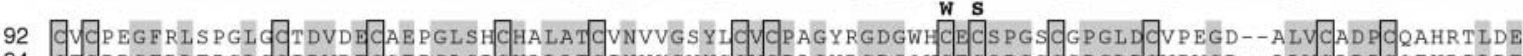

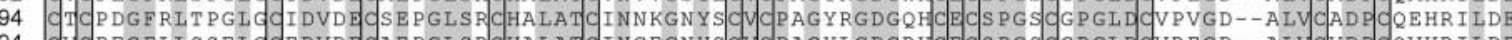

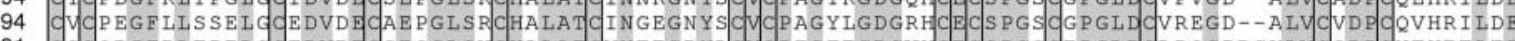

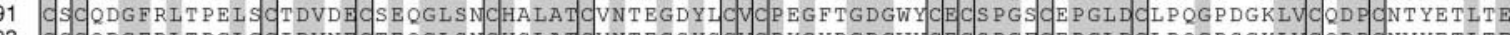

Homo sapiens Canis familiaris Bos taurus

Mus musculus Rattus norvegicus 18

183 YWRSTEYGEGYADDTDLRGWYRFVGQGGARMAETCVPVLRCNTAAPMWLNGTHPSS DEGIVSRKACAHWSGHCCLWDASVOVKA CAGGYYVYN 183 YWRSTEYGEGYACDTDLRGWYR VVG GGARMAET CVPVLR CNTAAPMWLNGTHPS DEGIVSRKACAHWSGHCC LWDASVOVKA CAGGYYVYN 185 YWRSTEYGAGYT CDVGLNGWYRFTGPGGVRLAETCVPVLHCNTAAPMWLNGTHPTRDQGIVNRTACAHWRGHCCLWDAS I OVKA CAGGYYVYN 84 YWRSTEYGVGYSCDAGLHGWYRETGQGGVRMAETCVPVLRCNTAAPMWLNGSHPSSSEGIVSRTACAHWSDOCCRWSTEIOVKACPGGFYIYN

Homo sapiens
Canis familiaris Bos taurus

Mus musculus Rattus norvegicus 279

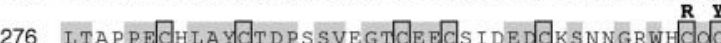
T76 LTAP E LAYCTDPSSVEGTCEECSIDEDCKSNNGRW LTETPECLAYCTDPTSVLGTCEECSVEELCKSHDGMWSCOCKODFNVTDLFLLDR-LECRPNDIKVSLSKCOLKSLGFEKVFMYLRDSOCSG 8 LTAP PECHLAYCT DPS SVEGTCE ECRVDEDCKSDNGEWHCOCKODFNVT D LS LLERRLECGVDDIKLS LSKCOLKSLGE KVFMYLHDSOCSG

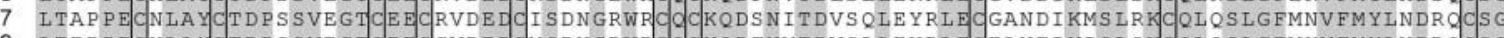

Homo sapiens 369 FNDRDNRDWVSVVTPARDGP DGTVLTRNETHATYSNTLYLADEIIIRDLNIKINFACSYPLDMKVSLKTALOPMVSALNIRVGGTGMFTVRMA Canis familiaris 370 FNERGDRDWVSVVT PARDGE CGTVMVRNETHATYSNTLYLADEIVIRDRNIKINFECSYPLDMKVSLETSLOPIVSSLNISVGGT GMFTVRMA

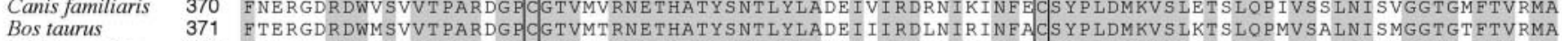
Mus musculus $\quad 370$ ESESDERDWMSI VT PARNGE GGTVLRRNETHATYSNT L YLANAI I I RDI I IRMNEECSYPLDMKVS LKT SLOPMV SALN I SLGGTGKETVRMA Rattus norvegicus 372 FSERGERDWMSIVTPARDGPLGTVLRRNETHATYSNTLYLASEIIIRDINIRINEECSYPLDMKVSLKTSLQPMVSALNISLGGTGKFTVQMA

Homo sapiens 462 LFQTPSYTQPYOGSSVTLSTEAFLYVGTMLDGGDLSRFALLMTNCYATPSSNATDPLKYFIIODRCPHTRDSTIOVVENGESSOGRFSVOMFR Canis familiaris 463 LFOTPDYTOPYOGSSVTLTTEAFLYVGTMLDGGDLSRFALLMTNCYATPSSNATDPLKYFI IODRCPRTTDSTIOVVENGESPQGRFSVOMFR

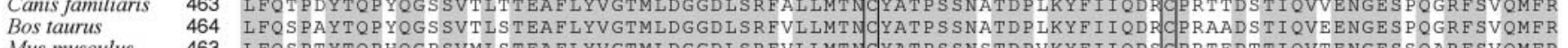
Mus musculus 463 Rattus norvegicus 465

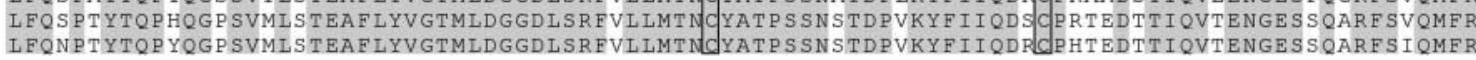

Homo sapiens Canis familiaris 556 Bostaurus $\quad 557$ Mus musculus $\quad 556$ $\begin{array}{ll}\text { Mus musculus } & 556 \\ \text { Rattus norvegicus } & 558\end{array}$

Figure 3. Multiple sequence alignment of human, dog, cow, mouse and rat uromodulin (GenBank AC NP_003352; AAO33163; NP_776638; NP_033496; NP_058778; respectively). Conserved amino acids are shaded in gray. The 48 invariant cysteine residues are boxed. Cysteine residues that are affected by the four missense mutations identified in this study (C148W, C150S, C315R and C317Y) are marked.

fibrillar complexes within the ER. Transient transfections of mutant UMOD constructs revealed a delay in the export of mutant protein to the plasma membrane that is due to a retarded transit of mutant protein through the ER. We hypothesize that defective uromodulin trafficking due to protein misfolding is an important factor in the pathogenesis of MCKD/FJHN and GCKD.

Uromodulin contains a N-terminal signal peptide (the cleavage site is most likely located between positions 23 and $24)$; three calcium binding epidermal growth factor (cbEGF)like domains between positions 31 and 148 and a fourth potential cbEGF-like domain at position 281-336; a zona pellucida (ZP) domain from amino acid 336 to 585 and a glycosyl phosphatidylinositol (GPI) anchor attachment site at position 614. EGF-like domains are widely distributed throughout the animal kingdom and are almost invariably found in a variety of secreted proteins or in the extracellular domain of membrane-bound proteins. Their functional significance is not yet clear. They contain six conserved cysteine residues ( $\mathrm{C} 1-\mathrm{C} 6$, respectively) that form disulfide bondsbetween $\mathrm{C} 1$ and $\mathrm{C} 3$, between $\mathrm{C} 2$ and $\mathrm{C} 4$, between $\mathrm{C} 5$ and C6 - that are important to establish the correct domain tertiary structure (21). ZP domains are present in many extracellular eukaryotic proteins including uromodulin, sperm receptors ZP1 and ZP2, glycoprotein-2 (GP2), $\alpha$ - and $\beta$-tectorins and transforming growth factor (TGF)- $\beta$ receptor III. ZP modules are involved in the polymerization of extracellular proteins into filaments with a helical superstructure (22). ZP domain proteins contain single transmembrane domains or GPI anchors that are crucial for protein assembly and are missing in the secreted mature proteins. ZP and probably the EGF-like domains are important for uromodulin polymerization into the $10-15 \mathrm{~nm}$ fibers observed by Wiggins (23).

Including the four new mutations reported in this study, 13 mutations in the uromodulin gene have been reported so far in $12 \mathrm{MCKD} / \mathrm{FJHN}$ and one GCKD families. Interestingly, 10 mutations are non-conservative substitutions affecting cysteine residues and one is a glycine to cysteine change. Among the reported $U M O D$ mutations seven affect cysteine residues in cbEGF-like domains II, III and IV. Furthermore, two additional mutations localize to cbEGF-like domains and affect glycine residue 103 (to cysteine), a change that probably affects the disulfide bond pattern, and the conserved asparagine residue 128 , that is predicted to be part of the calcium coordinating site (9).

Mutations affecting the disulfide bond pattern probably cause domain misfolding with a damaging effect on the global protein structure. The same effect can be hypothesized for mutations that reduce the calcium-binding affinity since bound calcium stabilizes the cbEGF-like domain conformation restricting interdomain flexibility $(24,25)$ and has a protective role against proteolytic degradation (26). The effect of uromodulin missense mutations that affect cysteine residues 150,217 and 255 is more difficult to predict since they are 


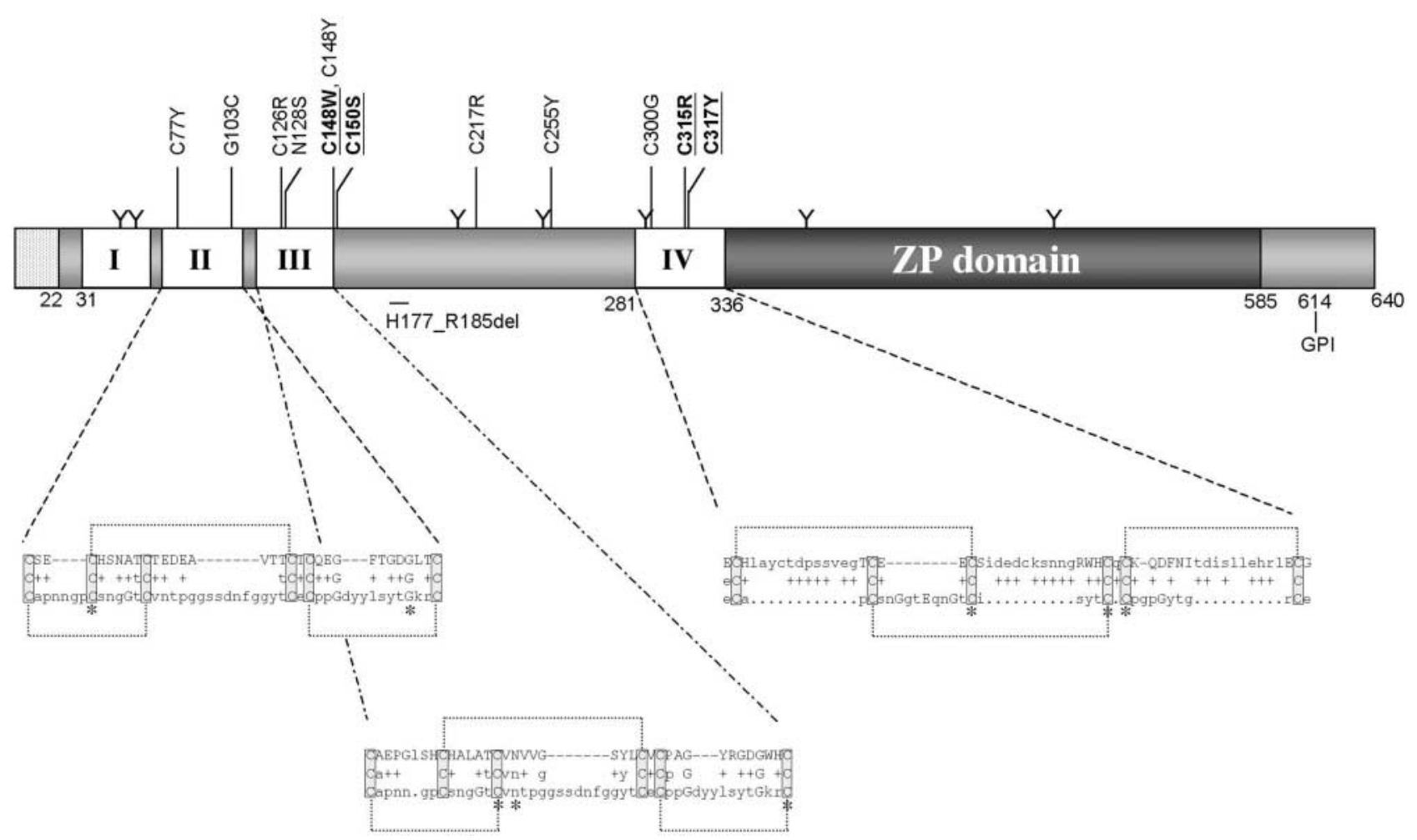

Figure 4. Structure of uromodulin protein. Leader peptide is shown as a dotted box, cbEGF-like domains are displayed as numbered white boxes. Positions of the ZP domain and the GPI-anchor attachment site are indicated. The seven glycosylation sites are marked as Y. The position and description of the 13 uromodulin mutations that have been reported so far are shown. Mutations reported in this study are underlined; references to other studies are shown in brackets. The amino acid sequence of cbEGF-like domains II, III and IV is shown (top line) aligned with the EGF-like consensus sequence (bottom line) from Pfam database (PF00008) for domains II and III and SMART database (SM00181) for domain IV. Conserved residues and conservative substitutions are indicated (mid line). Disulfide bonds $\mathrm{C} 1-\mathrm{C} 3, \mathrm{C} 2-\mathrm{C} 4, \mathrm{C} 5-\mathrm{C} 6$ for each cbEGF-like domain are shown as dotted lines and cysteine residues $\mathrm{C} 1$ to $\mathrm{C} 6$ are boxed. The position of uromodulin mutations that hit residues belonging to EGF-like domains is marked with an asterisk.

localized in a protein region (residues 149-280) that has no sequence similarity to any known protein domain. Nevertheless, the strong conservation of this protein segment among uromodulin homologs suggests that it is important for protein function. Furthermore, since no free sulfydryl group has been detected in uromodulin (18), these cysteine residues are probably involved in intramolecular disulfide bond formation, thereby contributing to protein folding.

In transfected cells that expressed uromodulin mutant isoforms, the amount of protein exposed on the plasma membrane was dramatically reduced. This difference was clear at early times after transfection but became eventually undetectable by $40-48 \mathrm{~h}$ after transfection when all the transfected cells were very intensely labeled. This 'saturationeffect' was observed both in HEK293 and HeLa cells and is presumably due to the accumulation of uromodulin on the plasma membrane as a consequence of the high expression rate of transiently transfected wild-type and mutant constructs. Even though we cannot exclude that some protein is eventually released to the media, as shown in stably transfected HeLa cells (27) and even assuming the existence in these cells of the not yet identified specific protease activity that releases membraneanchored uromodulin from tubular cells $(28,29)$, it is very likely that the rate at which the protein is exported to the plasma membrane overwhelms the one at which it is secreted.
By FACS experiments, we observed a significant reduction of the number of uromodulin-exposing cells for mutants C148W, C150S and C315R. However, when transfecting with the $\mathrm{C} 317 \mathrm{Y}$ isoform, the percentage of positive cells differed from the wild-type only at early stages after transfection, while it reached comparable values by $10 \mathrm{~h}$ after transfection. These results suggest that there might be a difference in the extent to which the different mutations affect uromodulin export dynamics with mutation C150S being the most severe and mutation $\mathrm{C} 317 \mathrm{Y}$ being the least severe one. Interestingly, the milder effect of mutation $\mathrm{C} 317 \mathrm{Y}$ seems to correlate with the milder phenotype of affected members of family MCKD\#1 that carry the mutation.

Since the mutant isoforms are predicted to impair the proper folding of uromodulin, we hypothesized the delayed export to the plasma membrane to be due to a longer retention time in the ER, where the proper set of disulfide bonds is formed by resident disulfide isomerases. Indeed, at short times after transfection, most wild-type uromodulin localized to the Golgi apparatus while mutant isoforms mainly localized in the ER, with little if any signal in the Golgi.

When transfected cells were cultured in reducing conditions, wild-type uromodulin behaved very similarly to the mutant isoforms and the extent of the maturation delay was proportional to the concentration of the reducing agent. 


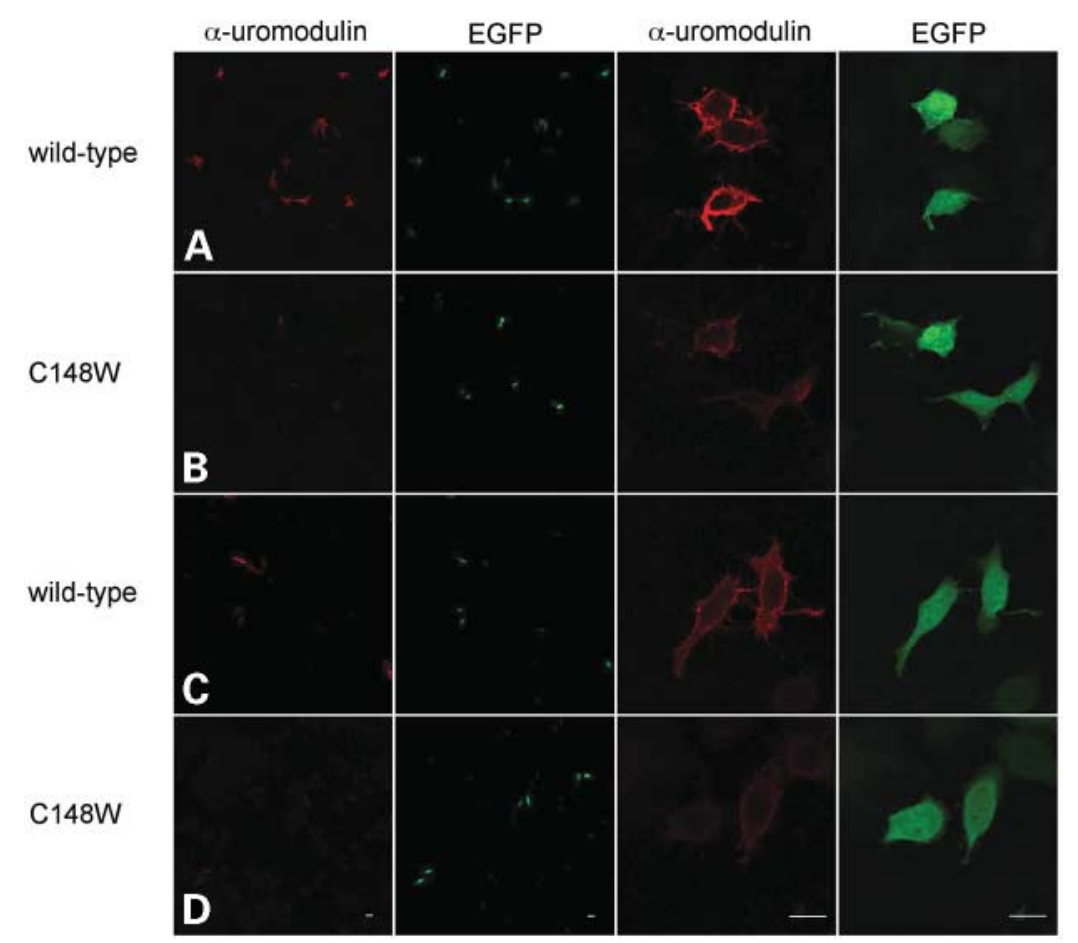

Figure 5. Immunofluorescence localization of wild type and mutant uromodulin in transiently transfected cells. Rows A and B, transfected HEK293 cells; rows C and D, transfected HeLa cells. Unpermeabilized cells were fixed in 4\% PFA either 4h (HEK293) or $6 \mathrm{~h}$ (HeLa) after transfection. Cells were cotransfected with an EGFP expressing plasmid and either wild-type or mutant $(\mathrm{C} 148 \mathrm{~W})$ uromodulin construct. Bar $=20 \mu \mathrm{m}$.

These results agree with previous studies that showed a reduced maturation rate of uromodulin in stably transfected cells cultured in reducing conditions (27) and substantiate the evidence that the formation of the correct set of disulfide bonds is the key step in uromodulin maturation that is affected by C148W, C150S, C315R and C317Y mutations.

A similar effect of cysteine-affecting mutations on protein maturation/export dynamics has been reported for other proteins, such as fibrillin-1 whose cbEGF-like domains share remarkable sequence homology to uromodulin ones. As demonstrated (30), the replacement of cysteine residues within fibrillin-1 cbEGF-like domain leads to a longer intracellular retention.

The fate of misfolded proteins in the lumen of the ER is thought to be retrotranslocation to the cytoplasm through a translocon composed of Sec 61, ubiquitination and proteasome-mediated degradation (31,32). In some pathologic conditions, however, the mutant protein can form degradation-resistant aggresomes that are accumulated either in the ER (33) or more often in the cytoplasm. Consistently, we showed the presence of uromodulin positive globular aggregates within the cytoplasm of tubular cells in kidney biopsies of MCKD/ FJHN and GCKD patients. EM findings, showing fibrillar material mostly evident in ER, agree with the intracellular distribution observed in cells that were transfected with uromodulin mutant isoforms. Based on these results we hypothesize that mutant uromodulin transit through the ER is delayed and the protein eventually accumulates in the ER or within the cytoplasm, possibly in compartments of ER origin. Uromodulin aggregates could occur by either intermolecular disulfide bonds or abnormal polymerization of the misfolded protein.

Urinary excretion of uromodulin is dramatically reduced in the affected members of family MCKD\#1. The extent of the reduction seems to exceed the expected one in the case of a heterozygous mutation and suggests a possible dominant negative effect. Possibly, the formation of intermolecular disulfide bonds involving the spare cysteine residue of a mutant molecule and its counterpart belonging to a wild-type isoform, as shown for fibrillin-1 mutants (34), may support this mechanism. However, the hypothesis of a dominant negative effect of uromodulin mutants is not fully supported by immunofluorescence and FACS experiments, which showed an intermediate cellular phenotype in the simulated heterozygous state. Nonetheless, we cannot exclude that a dominant negative mechanism might require a long time to establish, i.e. the 'chronic' expression of the mutant allele as opposed to the 'acute' one of transiently transfected cells. Also, uromodulin overexpression and the use of cell types other than TAL tubular cells could be further biases. Some of the clinical and pathologic characteristics of patients with MCKD/FJHN and GCKD such as low urine osmolality and tubulo-interstitial fibrosis could be explained on the basis of the failure of uromodulin function and the presence of intracellular/interstitial mutant uromodulin deposits. A possible explanation of the pathogenetic mechanisms leading to other features such as the formation of medullary (MCKD) and cortical (GCKD) cysts and hyperuricemia remains more difficult to establish.

There are some discrepancies in the literature regarding uromodulin membrane distribution in the distal tubule cells. 

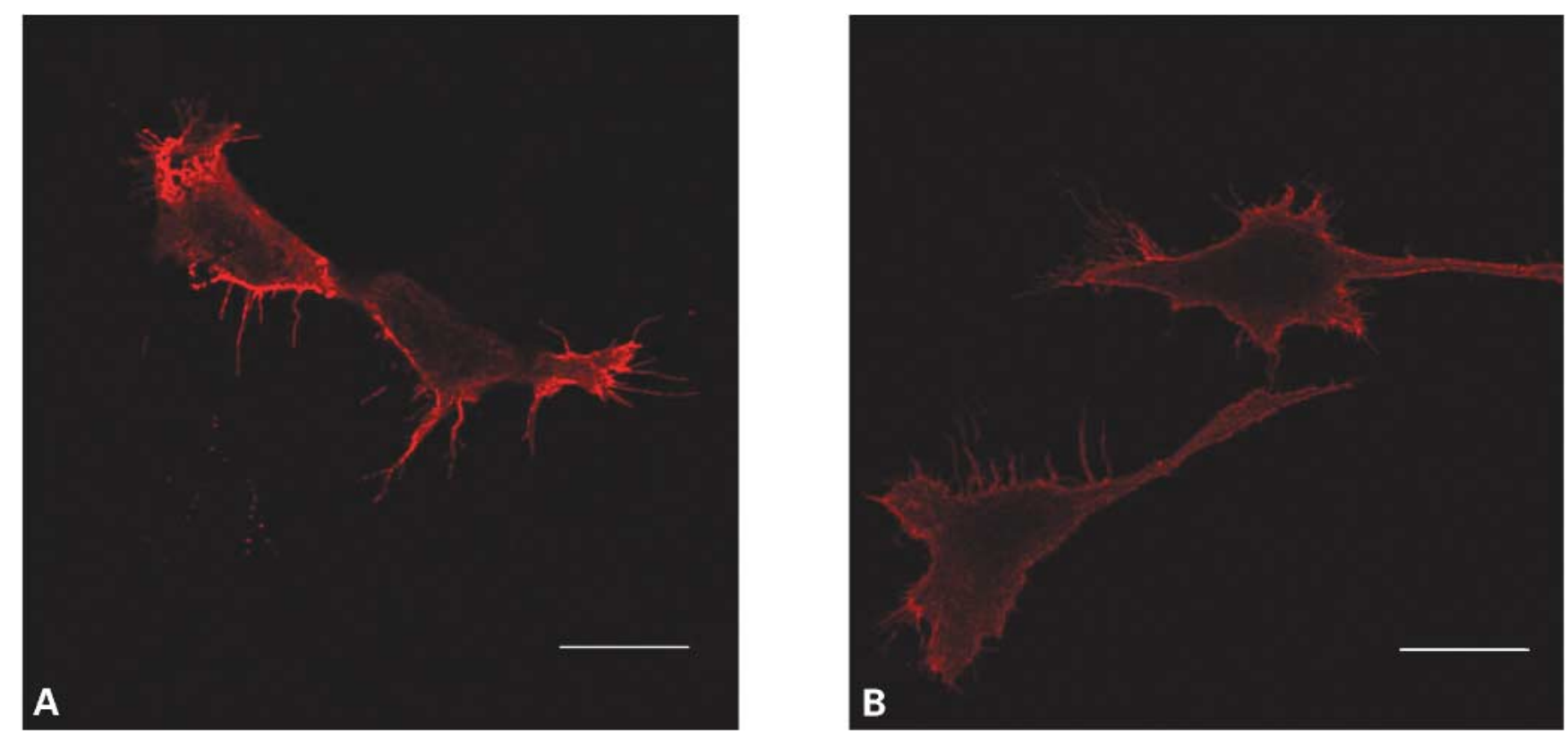

Figure 6. Uromodulin-positive membrane projections in unpermeabilized HEK293 (A) and HeLa (B) cells that were transfected with wild-type uromodulin. Cells were fixed either $4 \mathrm{~h}$ (HEK293) or $6 \mathrm{~h}$ (HeLa) after transfection. Bar $=20 \mu \mathrm{m}$.

While most studies demonstrated uromodulin localization on the apical plasma membrane of the TAL and DCT tubular cells $(10,11,35,36)$, few of them were able to show its presence on the basolateral membrane of the TAL cells $(11,36)$. Nevertheless, uromodulin exclusive expression in epithelial cells of the TAL and DCT is well established. It has also been shown that uromodulin monomer can polymerize into $10-15 \mathrm{~nm}$-wide fibers that form a reversible gel-like structure (23) that is water impermeable and allows ion movement (14). Taking into account its localization and physicochemical properties and the electrolyte/water permeability of these nephron segments, it has been proposed that uromodulin has a role in salt transport in the TAL and DCT and water impermeability of the TAL, a process that is crucial for urine concentration. Studies on rats fed with different dietary salt load showed that uromodulin mRNA and protein levels were increased in a high-salt diet. Furthermore, administration of furosemide, a loop diuretic that binds to the $\mathrm{Na}-\mathrm{K}-2 \mathrm{Cl}$ cotransporter (NKCC2) in the thick ascending limb blocking ion transport (37), further increased uromodulin mRNA levels in rats on a high-salt diet (38). These results support the hypothesis of an involvement, albeit secondary, of uromodulin in salt uptake in the TAL. At the same time, failure of uromodulin to properly form the water barrier that impermeabilizes the TAL could explain the marked defect in the urine-concentrating process that determines a constant and most typical low urine osmolality in patients affected by these disorders.

A typical clinical feature of MCKD/FJHN patients also present in family GCKD\#1 is tubulo-interstitial fibrosis. Although uromodulin has been implicated in urothelial defense against infection (39), which may lead to fibrosis through pathogen-induced local inflammation, it seems unlikely that the tubulo-interstitial fibrosis of MCKD/FJHN and GCKD is due to the lack of uromodulin protective role. In fact, urinary infections are not increased in our MCKD/FJHN and GCKD patients.

Several observations have lead to the hypothesis that uromodulin can also have an inflammatory potential (40) and tubulo-interstitial nephritis in the TAL can be induced in rabbit and rat following administration of uromodulin $(41,42)$.

We hypothesize that tubular cells that are unable to degrade the large amounts of misfolded mutant protein that is intracellularly accumulated eventually go into apoptosis. Cell debris would stimulate inflammation and fibroblast infiltration and would release uromodulin aggregates in the interstitium that could in turn induce an inflammatory response. Numerous studies demonstrated the presence of interstitial deposits of uromodulin in patients with tubulo-interstitial nephropathy, including MCKD cases (43-45). Often uromodulin accumulation in the interstitium is associated with infiltration of inflammatory cells and this is considered a pathologic event in the kidney that potentially triggers a pro-fibrotic cascade $(43,44)$.

The cellular mechanisms leading to the formation of medullary and glomerular cysts seem unexpected on the basis of uromodulin function. Medullary cysts are not a common feature in the MCKD patients we studied. Affected individuals of family MCKD\#9 had small kidneys without cysts and one affected member only (II-3) of family MCKD\#1 had medullary cysts. The small cysts described in MCKD patients could arise from tubule swelling. On the other hand, glomerular cysts are a common clinical feature in the affected members of family GCKD\#1. They can occur as an isolated manifestation or be associated with a variety of both glomerular and tubular diseases including autosomal dominant and recessive polycystic kidney and renal dysplasia or develop after an unrelated glomerular disease, as in hemolytic uremic syndrome (46). 
A
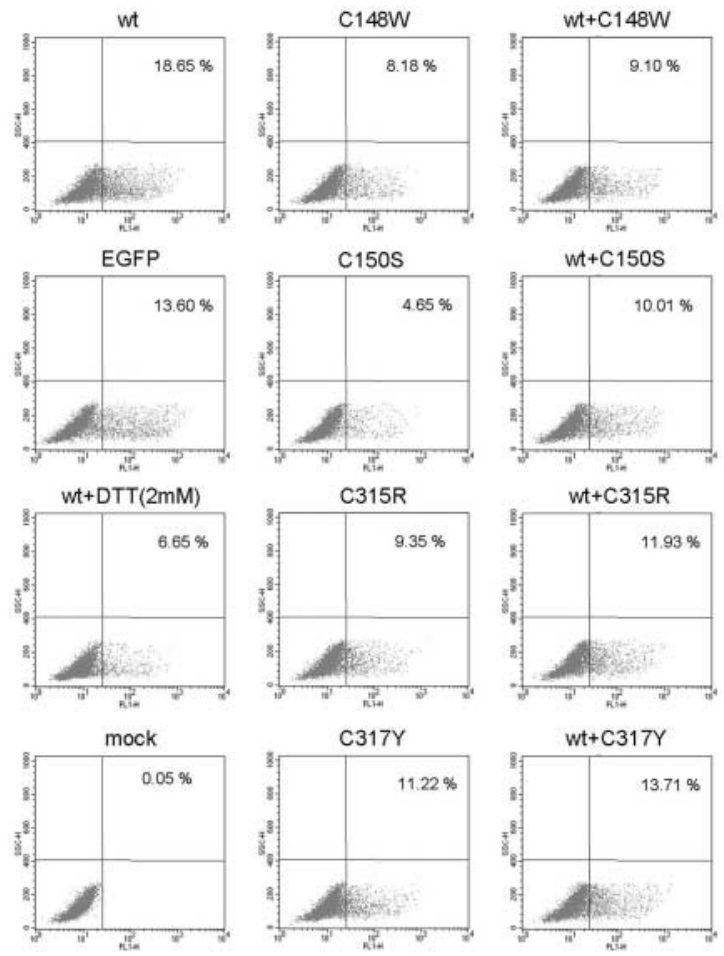

B

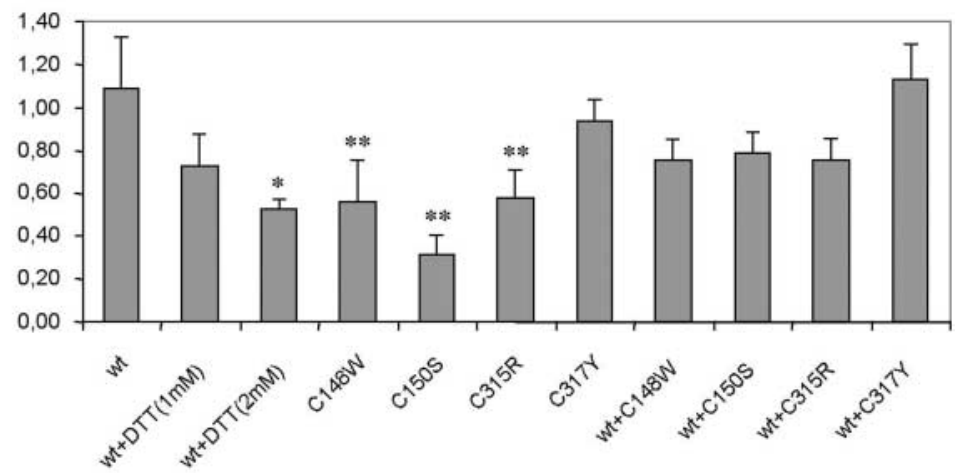

C

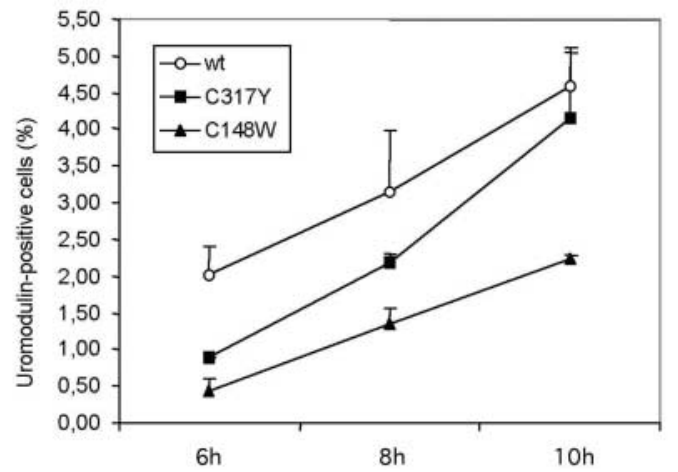

Figure 7. FACS analysis of uromodulin-positive HEK293 cells transfected with either wild-type or mutant constructs. EGFP-expressing plasmid was used as a transfection efficiency control. (A) Distributions of uromodulin positive cells at $14 \mathrm{~h}$ after transfection. (B) The number of uromodulin-positive cells is significantly reduced for mutants C148W, C150S and C315R and for cells expressing wild-type uromodulin and cultured in reducing conditions (2 mM DTT). Cells were collected $14 \mathrm{~h}$ after transfection. Uromodulin-positive cells were normalized by EGFP transfection. Average percentage values for six replicates are shown. $* P<0.05 ; * * P<0.01$ (Mann-Whitney two-tailed test). Bars represent \pm SD. (C) Time-course experiment showing the different export dynamics of mutant $\mathrm{C} 317 \mathrm{Y}$ as compared to mutant $\mathrm{C} 148 \mathrm{~W}$ and wild-type uromodulin. Cells were collected for FACS analysis at 6,8 and $10 \mathrm{~h}$ after transfection. Bars represent \pm SD. 


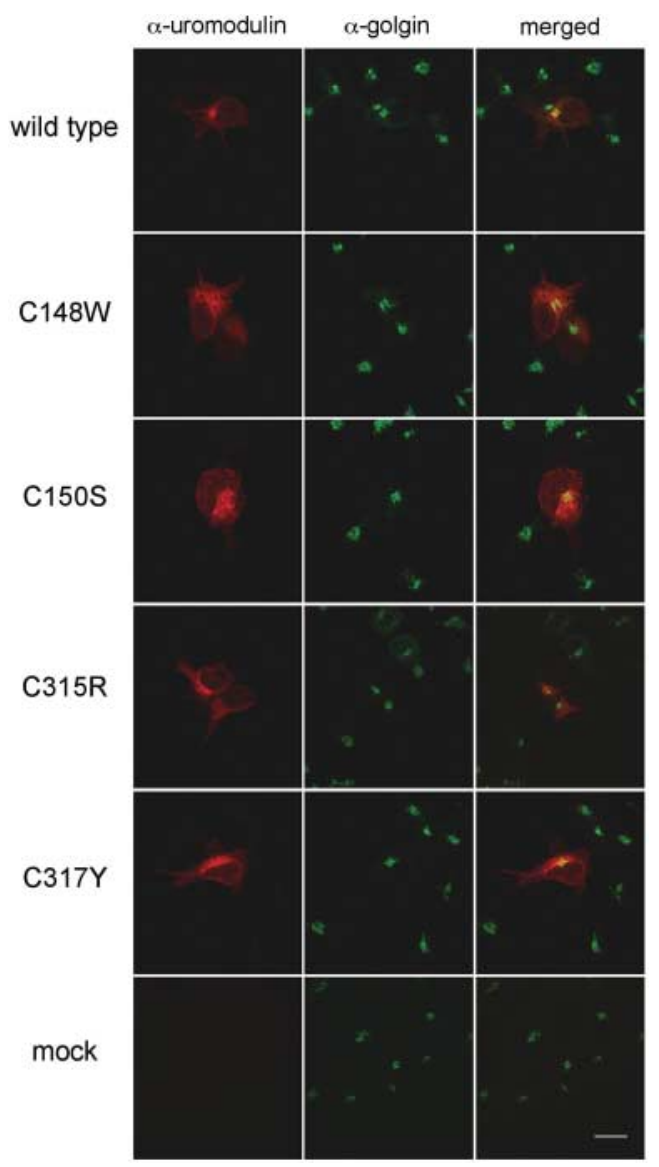

Figure 8. Intracellular localization: uromodulin and golgin staining. Permeabilized HEK293 cells were transfected, fixed $6 \mathrm{~h}$ after transfection and incubated with antiuromodulin and anti-golgin (Golgi marker). Wild-type uromodulin is mainly localized to the Golgi apparatus. $\mathrm{Bar}=16 \mu \mathrm{m}$.

A possible mechanism for glomerular cyst formation is tubular obstruction that would lead to urine reflux and extravasation, hence uromodulin interstitial deposits, and to an increased pressure in Bowman's space. Histochemical studies showing the abnormal presence of uromodulin within glomerular cysts support this possibility (44).

Along with a defect in the concentrating capability, hyperuricemia seems to be a common feature in all the families with $U M O D$ mutations that have been reported so far. The overall tubular reabsorption of urate in humans is a complex phenomenon based on a balance between true reabsorption, secretion and post-secretion reabsorption. All these phases should be confined to the proximal tubule (47) where the human urate transporters URAT1 and hUAT are endowed $(48,49)$. We hypothesize that hyperuricemia in MCKD/FJHN and GCKD patients is secondary to volume contraction. This may result from a reduced $\mathrm{NaCl}$ reabsorption in the TAL due to loss of water impermeability as a consequence of intracellular accumulation of mutant uromodulin. The decreased $\mathrm{Na}^{+}$ uptake in the TAL would be compensated by enhanced $\mathrm{Na}^{+}$ reabsorption in the proximal tubule thus increasing the activity of the urate transporter URAT1 (49).

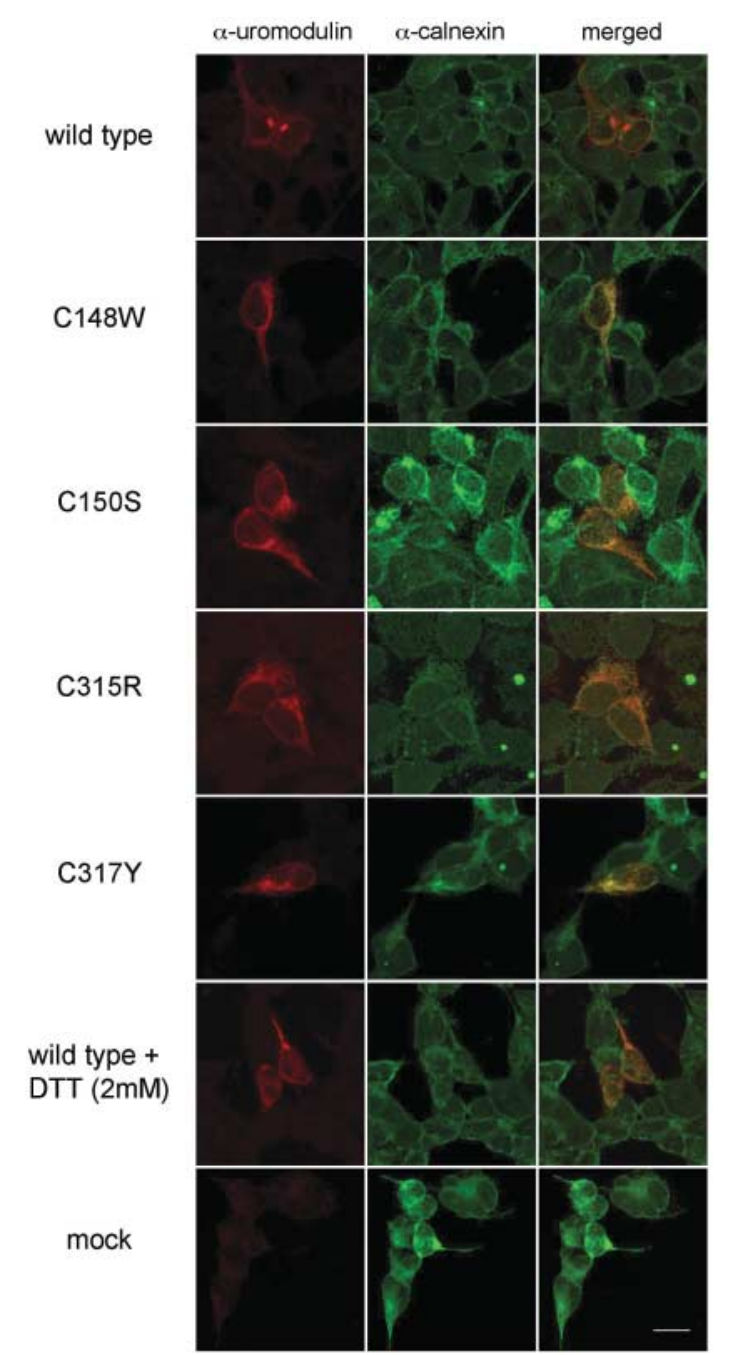

Figure 9. Intracellular localization: uromodulin and calnexin staining. Permeabilized HEK293 cells were transfected with either wild-type or mutant constructs, fixed $6 \mathrm{~h}$ after transfection and incubated with anti-uromodulin and anti-calnexin (ER marker). Mutant uromodulin mainly localizes to the ER. Wild-type uromodulin in cells cultured in reducing conditions shows the same localization pattern of mutant isoforms. Bar $=16 \mu \mathrm{m}$.

It seems interesting to note that some patients of family MCKD\#7 presented with either hyperuricemia or cortico-medullary cysts with or without uremia (see Table 1). The possible activity of modifier genes that could explain the interfamilial variability should be taken into account.

In conclusion, we have shown that mutations in the uromodulin gene are causative of different disorders such as MCKD/FJHN and GCKD. Clinical features common to all patients were the presence of tubulo-interstitial fibrosis, reduced urinary concentrating ability and, except in few cases, hyperuricemia. Interestingly, the vast majority of uromodulin mutations reported so far are likely to affect the protein folding. Consistently, we have provided evidences that uromodulin mutations affect the protein intracellular trafficking delaying its transit through the ER with chronic effect that discloses a functional/molecular/clinical correlation. This 

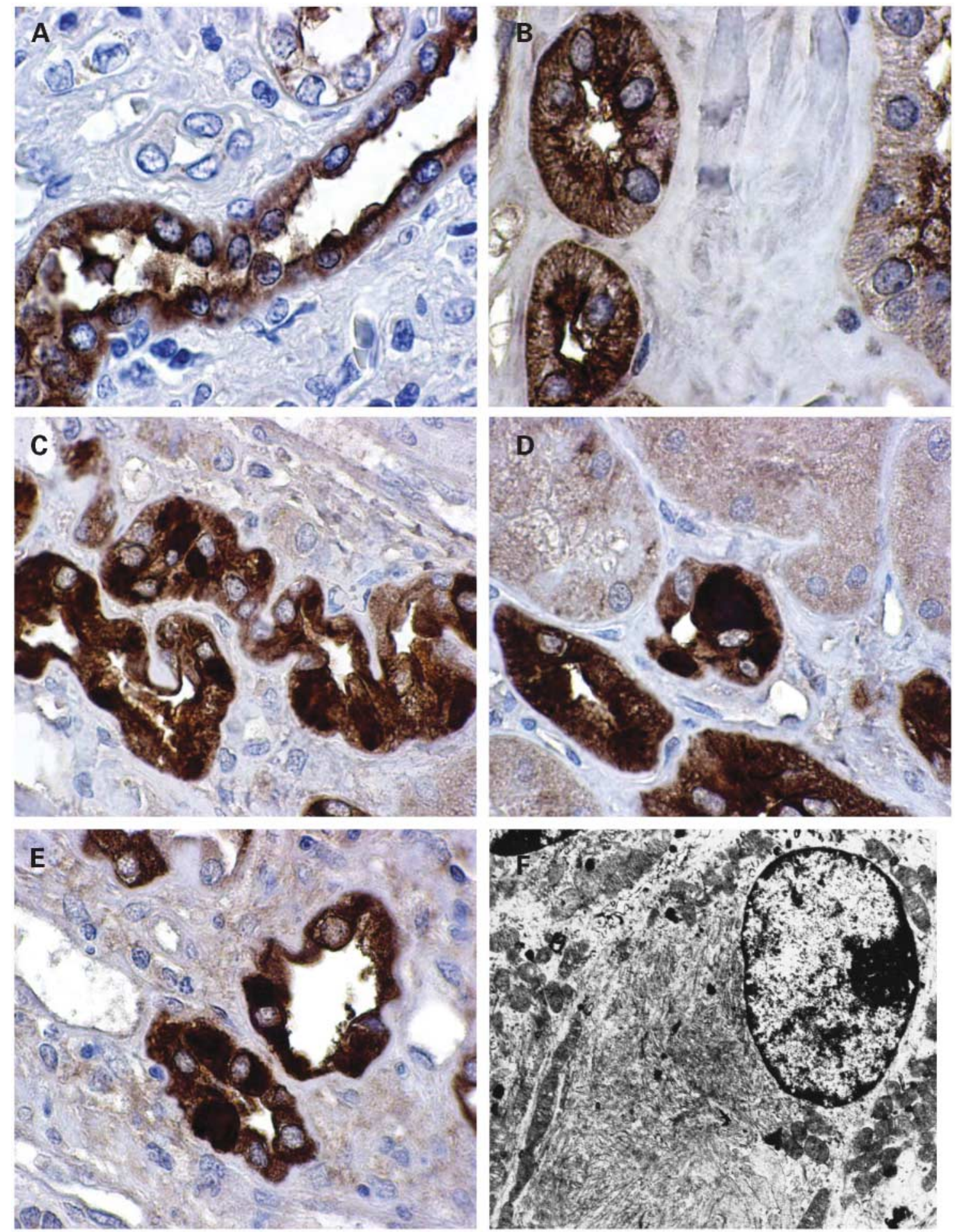

Figure 10. Intracellular aggregates of mutant uromodulin in epithelial cells of TAL and DCT. Kidney biopsy sections of control and patients are shown. (A, B) uromodulin staining in control biopsy, showing a diffuse cytoplasmic staining with apical reinforce $(100 \times)$. (C, D) patient IV-6 of family MCKD\#1 (E) patient IV-1 of family GCKD\#1 $(100 \times)$. In both patient biopsies uromodulin intracellular aggregates are evident. (F) Transmission electron microscopy of kidney biopsy from patient IV-6 of family MCKD\#1 showing abnormal fibrillar material mostly evident in the ER $(5700 \times)$.

eventually results in intracellular accumulation of uromodulin aggregates in tubular epithelial cells and significant reduction of secreted protein in patient urine. Further studies are required to elucidate the mechanisms through which intra- and extracellular deposits of uromodulin exert their renal toxicity. 

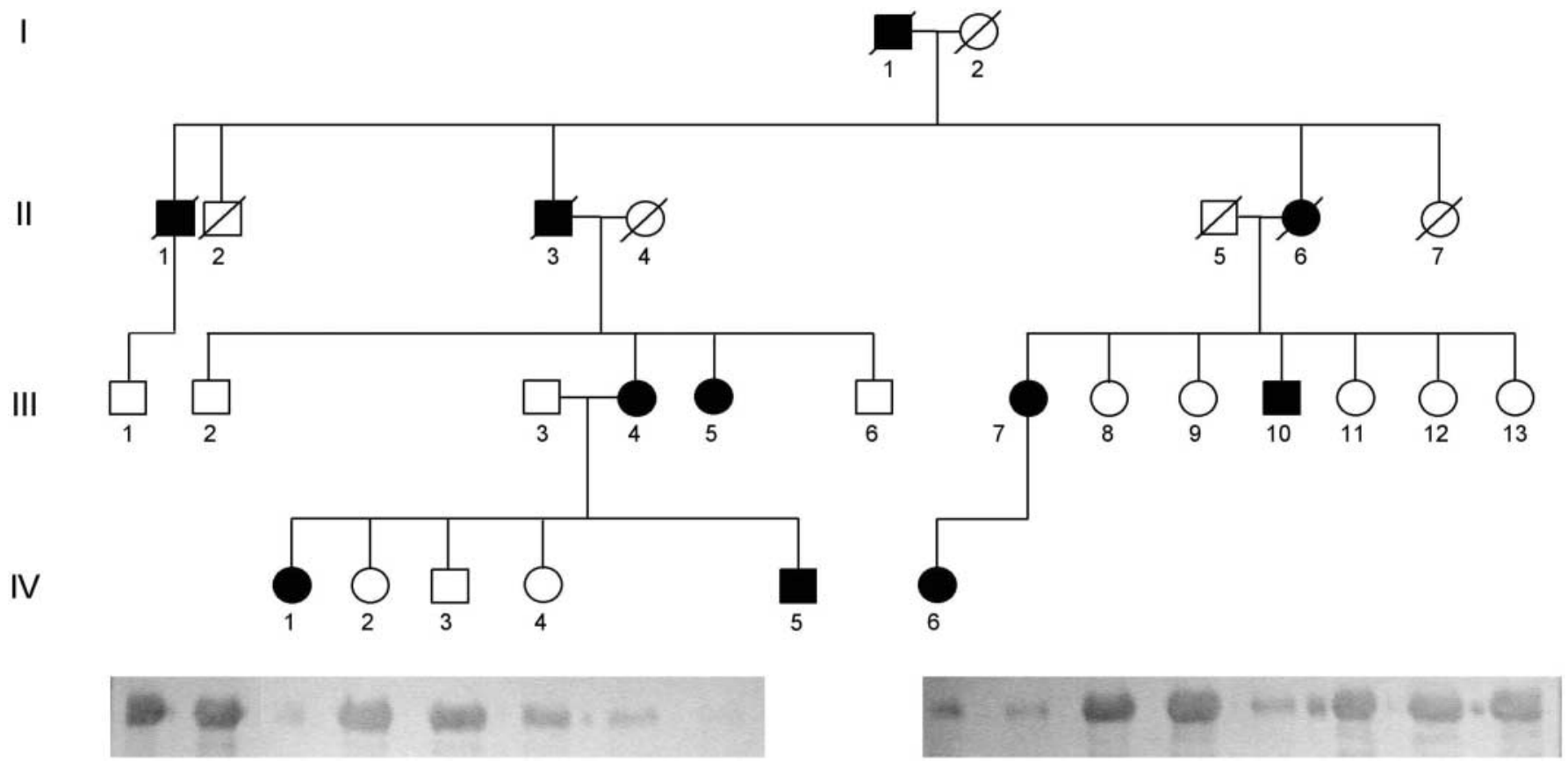

Figure 11. Uromodulin excretion is reduced in patients of family MCKD\#1. Western blot of total urine proteins was labeled with anti-uromodulin antibody.

\section{MATERIALS AND METHODS}

\section{Patients}

Families were investigated on the basis of a MCKD/FJHN clinical picture as defined by the following criteria: (a) history of renal insufficiency with inheritance compatible with an autosomal dominant trait; (b) stable low urinary osmolality in the first morning urine and lack of any compensatory effect after endonasal Minirin (two pushes); (c) history of gout and hyperuricemia (serum uric acid $>6 \mathrm{mg} \%$ ) due to low fractional excretion of uric acid $(<5 \%)$. In the absence of a clear history of gout, hyperuricemia was defined as a serum level of uric acid higher than one standard deviation of the normal values for age and sex; (d) renal biopsy showing tubulo-interstitial fibrosis with infiltrates, tubular atrophy and thickening of the tubular basal membrane with periodic acid Schiff-positive material. The family with GCKD included three patients in two generations that presented the above clinical features except point $d$. In particular, all presented mild polyuria associated with low urine density ( $<400 \mathrm{mOsm} \mathrm{H}_{2} \mathrm{O} / \mathrm{kg}$ ), slight increment of serum creatinine, hyperuricemia with decreased excretion fraction according to the enrolment criteria. Renal histology was characterized by marked dilation of Bowman's spaces affecting $40 \%$ of more than 100 glomeruli, with reduced or rudimentary glomerular tufts. Diffuse and mild interstitial fibrosis was observed.

\section{Mutation screening}

We isolated the genomic sequences spanning the UMOD gene from a phage human fibroblast genomic library (CAT 946204, Stratagene, La Jolla, CA, USA) using a $609 \mathrm{bp}$ fragment of UMOD cDNA (GenBank M15881; nt pos. 147-756) as a probe.
Intron-exon boundary sequences were determined by direct automated sequencing (ABI-PRISM 310 Genetic Analyzer, Applied Biosystems, Foster City, CA, USA) of lambda clones. PCR primers for the specific amplification of UMOD 12 exons (including non-coding exons 1 and 2) and intron/exon borders were designed using the Primer Express program (Applied Biosystems). Primer sequences are available upon request.

Mutation analysis was performed by direct sequencing of PCR products. Each exon was amplified from patient genomic DNA, purified (PCR Product Pre-Sequencing kit, USB, Cleveland, OH, USA) and sequenced using the BIG DYE dideoxy-terminator chemistry (Applied Biosystems) on an ABI 3100 DNA sequencer (Applied Biosystems). Chromas 1.5 software (Technelysium, Helensvale, Q1d, Australia) and LASERGENE package computer programs (DNASTAR, Madison, WI, USA) were used to edit, assemble and translate sequences. Mutation analysis was performed on two affected individuals from each MCKD/FJHN and GCKD family. Co-segregation analysis of mutations and mutation screening in 100 unrelated controls was performed by direct sequencing.

The conservation of the mutated amino acid residues was assessed by BlastP alignment of human wild-type protein and other mammalian uromodulin homologs (Bos taurus, Canis familiaris, Rattus norvegicus, Mus musculus). Protein pattern identification was performed by PIX analysis (www.hgmp.mrc. ac.uk), by Pfam analysis (www.sanger.ac.uk) and by using the ExPASy Proteomics tools (www.expasy.ch).

\section{Immunopathology and electron microscopy}

Immunopathology was performed on normal portions of kidneys removed for renal carcinoma, as well as on renal biopsies from patients IV-6 (family MCKD\#1) and IV-1 (family 
GCKD\#1). Tissues were fixed in paraformaldehyde and embedded in paraffin. Sections of $3 \mu \mathrm{m}$ thickness were first treated with microwaves for three cycles of 5 min each and then incubated with monoclonal anti-uromodulin antibodies (1032A clone; Cedarlane, Hornby, Ontario, Canada) diluted 1:32000 and $1: 1000000$, for $30 \mathrm{~min}$. After several washings in PBS, a goat anti-mouse IgG linked to biotin was incubated for further $30 \mathrm{~min}$ with gentle agitation. Staining was developed with streptavidin peroxidase for $15 \mathrm{~min}$ and diaminobenzidin.

For transmission electron microscopy tissues were fixed in $2.5 \%$ glutaraldehyde phosphate buffer $0.1 \mathrm{M}(\mathrm{pH} 7.2)$ for $3 \mathrm{~h}$, post-fixed in $1 \%$ osmium tetroxide, dehydrated in alcohol and propylene oxide and then embedded in Epon 100. Semi-thin sections $(0.5 \mu \mathrm{m})$ were stained with methylene blue and saphranine and inspected under microscope to cut regions for ultra-thin sections. Ultra-thin sections were stained with uranyl acetate and lead citrate, and subsequently mounted on copper grids. They were analyzed with a Philips EM 301 electron microscope at $60 \mathrm{kV}$.

\section{Uromodulin expression constructs and site-directed mutagenesis}

We derived uromodulin full-length cDNA by RT-PCR on human kidney cDNA (MTC panel, BD Biosciences Clontech, Palo Alto, CA, USA) using primers: forward 5'-CCCAAGCTTACAAG TAGCGGGAAGAGCAGAAAGG-3' (HindIII tail); reverse 5'-CGGAATTCATAGGGAGAAAAGAAGGCAGGC-3' (EcoRI tail). The PCR product was gel purified and cloned into the expression vector pcDNA3.1 (Invitrogen). We mutated uromodulin cDNA by using the QuickChange site-directed mutagenesis kit (Stratagene). We introduced the four mutations identified in MCKD/FJHN and GCKD patients: 444T $>\mathrm{G}$ (codon TGT $>$ TGG,$\quad$ C148W $) ; \quad 449 \mathrm{G}>\mathrm{C} \quad(\mathrm{TGC}>\mathrm{TCC}, \mathrm{C} 150 \mathrm{~S})$; 943T $>$ C $($ TGC $>$ CGC, C315R $) ; 950 G>A \quad($ TGC $>$ TAC, $\mathrm{C} 317 \mathrm{Y}$ ). The primer pairs used for site-directed mutagenesis are $\left(5^{\prime}\right.$ to $\left.3^{\prime}\right)$ : C148mutf, GGATGGATGGCACTGGGAGTGCT CCCCGGG; C148mutr, CCCGGGGAGCACTCCCAGTGCC ATCCATCC; C150mutf, GATGGCACTGTGAGTCCTCCCC GGGCTCCTG; C150mutr, CAGGAGCCCGGGGAGGACT CACAGTGCCATC; C315mutf, AATGGCAGATGGCACCG CCAGTGCAAACAGG; C315mutr, CCTGTTTGCACTGGC GGTGCCATCTGCCATT; C317mutf, GATGGCACTGCCAG TACAAACAGGACTTCAAC; C317mutr, GTTGAAGTCCT GTTTGTACTGGCAGTGCCATC. Constructs were fully re-sequenced.

\section{Western blot}

Transfection was carried out by using Metafectene (Biontex, Munich, Germany) according to the manufacturer's instructions. We used $1 \mu \mathrm{g}$ of plasmid DNA for $2.6 \times 10^{6}$ cells. We changed media $2 \mathrm{~h}$ after transfection and let cells grow for $12 \mathrm{~h}$. Cells were collected in Versene (Invitrogen) and lysed in 1\% NP-40 (Nonidet P-40 detergent, Sigma-Aldrich, St Louis, MO, USA), $50 \mathrm{~mm}$ Tris $\mathrm{pH} 7.5,150 \mathrm{~mm} \mathrm{NaCl}$. Proteins were quantified by using the Bio-Rad Protein Assay (Bio-Rad, Hercules, CA, USA). We loaded equal amounts of proteins $(70 \mu \mathrm{g})$ on reducing SDS-PAGE. We incubated transblotted nitrocellulose membranes with goat polyclonal antibody against uromodulin (ICN Biomedicals, Irvine, CA, USA; $1: 1000$ dilution) followed by incubation with horseradish peroxidase-conjugated secondary antibody (Promega, Madison, WI, USA; $1: 2000$ dilution). Protein bands were visualized with the Enhanced Chemiluminescence kit (Amersham Biosciences, Piscataway, NJ, USA).

Twenty four-hour urine collections were obtained from affected and non-affected members of family MCKD\#1 and maintained in timole. MCKD\#1 patients showed a mild polyuria with a urinary volume ranging from 1400 to $2000 \mathrm{ml} / 24 \mathrm{~h}$. After centrifugation of $100 \mathrm{ml}$ urine at $1000 \mathrm{~g}$, supernatants were first dialyzed against water for $24 \mathrm{~h}$ with several changes and then lyophilized. Since proteinuria was below the normal range of excretion $(<150 \mathrm{mg} / 24 \mathrm{~h})$ in affected and non-affected members, equal amounts of proteins $(50 \mu \mathrm{g})$ were loaded to the gel track and separated on SDS-PAGE.

\section{Immunofluorescence experiments}

Cells were grown for $16 \mathrm{~h}$ prior to transfection on glass cover slips in 12-well plates (Corning Life Sciences). Transfections were carried out as above using $500 \mathrm{ng}$ of plasmid DNA for $10^{6}$ cells. Heterozygotes were simulated by cotransfecting equal amounts $(250 \mathrm{ng})$ of wild-type and mutant plasmid DNA. Transfection efficiency was determined by cotransfecting with enhanced green fluorescent protein (EGFP) expressing vector pcDNA3x $(+)$ MyEGFP (Invitrogen). Fresh media was added $2 \mathrm{~h}$ after transfection. For cells cultured in reducing conditions, added media contained $2 \mathrm{~mm}$ DTT. Cells were fixed at different times after transfection $(4,6,8,12,20,40,48,50$ and $74 \mathrm{~h})$ either in $4 \%$ PFA for $30 \mathrm{~min}$ at $37^{\circ} \mathrm{C}$ (unpermeabilized cells) or in $100 \%$ methanol for $5 \mathrm{~min}$ at $-20^{\circ} \mathrm{C}$ (permeabilized cells). Unpermeabilized and permeabilized cells were incubated with pre-immune donkey serum for $30 \mathrm{~min}$ at $37^{\circ} \mathrm{C}$. Cells were then incubated with goat polyclonal primary antibody against uromodulin (ICN Biomedicals; 1:500 dilution). Permeabilized cells were also stained using sheep anti-golgin (Molecular Probes, Eugene, OR, USA; 1:300; Golgi marker) and sheep anti-calnexin (Sigma-Aldrich; 1:500; ER marker). We washed cells in phosphate-buffered saline solution and incubated with appropriate secondary antibodies $(1: 1000)$ : AlexaFluor 594-conjugated donkey secondary antibody against goat IgG (Molecular Probes); AlexaFluor 488-conjugated donkey secondary antibody against sheep IgG (Molecular Probes). We placed cells in fluorescent mounting medium (DakoCytomation, Glostrup, Denmark) over microscope slides and visualized them under confocal microscope Leica TCS SP2 AOBS (Leica Microsystems, Bannockburn, IL, USA).

\section{Cell sorting experiments}

Transfections were carried out as above (see western blot section). Cells were collected in Versene (Invitrogen) at 6,8 and $10 \mathrm{~h}$ after transfection and resuspended in $\alpha \mathrm{MEM}+\mathrm{FBS} 2 \%$ $\left(2.4 \times 10^{6} \mathrm{cells} / \mathrm{ml}\right)$. Cells were incubated with polyclonal antibody anti-uromodulin (ICN Biomedicals; 1:1000/ 700000 cells) for $30 \mathrm{~min}$ at $4^{\circ} \mathrm{C}$ and washed with aMEM + FBS $2 \%$. Cells were incubated for $30 \mathrm{~min}$ at $4^{\circ} \mathrm{C}$ with the secondary antibody: polyclonal donkey anti goat Alexa 488 conjugated (1:2500/700 000 cells; Molecular Probes). 
Cells were washed with $\alpha$ MEM + FBS $2 \%$, resuspended in $300 \mu 1$ of $\alpha \mathrm{MEM}+\mathrm{FBS} 2 \%$ and incubated $10 \mathrm{~min}$ at RT with 7amino-actinomycin $\mathrm{D}$ (7AAD) for the exclusion of nonviable cells. Cell fluorescence was measured by flow cytometry (FACSCalibur, BD Biosciences) and analyzed by CellQUEST software (BD Biosciences).

\section{ACKNOWLEDGEMENTS}

We thank Cesare Covino for his technical assistance with confocal microscope. This study was supported by grants from the Italian Telethon Foundation (GP0400Y02), the Italian Ministry of University and Research (MIUR, COFIN 2002) and from IRCCS Burlo Garofolo, Trieste.

\section{REFERENCES}

1. Gusmano, R., Caridi, G., Marini, M., Perfumo, F., Ghiggeri, G.M., Piaggio, G., Ceccherini, I. and Seri, M. (2002) Glomerulocystic kidney disease in a family. Nephrol. Dial. Transplant., 17, 813-818.

2. Christodoulou, K., Tsingis, M., Stavrou, C., Eleftheriou, A., Papapavlou, P. Patsalis, P.C., Ioannou, P., Pierides, A. and Constantinou Deltas, C. (1998) Chromosome 1 localization of a gene for autosomal dominant medullary cystic kidney disease. Hum. Mol. Genet., 7, 905-911.

3. Scolari, F., Puzzer, D., Amoroso, A., Caridi, G., Ghiggeri, G.M., Maiorca, R., Aridon, P., De Fusco, M., Ballabio, A. and Casari, G. (1999) Identification of a new locus for medullary cystic disease, on chromosome $16 \mathrm{p} 12 . \mathrm{Am} . J$. Hum. Genet., 64, 1655-1660.

4. Stiburkova, B., Majewski, J., Sebesta, I., Zhang, W., Ott, J. and Kmoch, S. (2000) Familial juvenile hyperuricemic nephropathy: localization of the gene on chromosome 16p11.2 and evidence for genetic heterogeneity. Am. J. Hum. Genet., 66, 1989-1994.

5. Kamatani, N., Moritani, M., Yamanaka, H., Takeuchi, F., Hosoya, T. and Itakura, M. (2000) Localization of a gene for familial juvenile hyperuricemic nephropathy causing underexcretion-type gout to $16 \mathrm{p} 12$ by genome-wide linkage analysis of a large family. Arthritis Rheum., 43, 925-929.

6. Dahan, K., Fuchshuber, A., Adamis, S., Smaers, M., Kroiss, S., Loute, G., Cosyns, J.P., Hildebrandt, F., Verellen-Dumoulin, C. and Pirson, Y. (2001) Familial juvenile hyperuricemic nephropathy and autosomal dominant medullary cystic kidney disease type 2: two facets of the same disease? J. Am. Soc. Nephrol., 12, 2348-2357.

7. Stacey, J.M., Turner, J.J., Harding, B., Nesbit, M.A., Kotanko, P., Lhotta, K., Puig, J.G., Torres, R.J. and Thakker, R.V. (2003) Genetic mapping studies of familial juvenile hyperuricemic nephropathy on chromosome 16p11p13. J. Clin. Endocrinol. Metab., 88, 464-470.

8. Hart, T.C., Gorry, M.C., Hart, P.S., Woodard, A.S., Shihabi, Z., Sandhu, J., Shirts, B., Xu, L., Zhu, H., Barmada, M.M. et al. (2002) Mutations of the UMOD gene are responsible for medullary cystic kidney disease 2 and familial juvenile hyperuricaemic nephropathy. J. Med. Genet., 39, 882-892.

9. Turner, J.J., Stacey, J.M., Harding, B., Kotanko, P., Lhotta, K., Puig, J.G., Roberts, I., Torres, R.J. and Thakker, R.V. (2003) Uromodulin mutations cause familial juvenile hyperuricemic nephropathy. J. Clin. Endocrinol. Metab., 88, 1398-1401.

10. Bachmann, S., Koeppen-Hagemann, I. and Kriz, W. (1985) Ultrastructural localization of Tamm-Horsfall glycoprotein (THP) in rat kidney as revealed by protein A-gold immunocytochemistry. Histochemistry, 83, 531-538.

11. Peach, R.J., Day, W.A., Ellingsen, P.J. and McGiven, A.R. (1988) Ultrastructural localization of Tamm-Horsfall protein in human kidney using immunogold electron microscopy. Histochem. J., 20, 156-164.

12. Tamm, I. and Horsfall, F.L. (1950) Characterisation and separation of an inhibitor of viral hemagglutination present in urine. Proc. Soc. Exp. Biol. Med., 74, 108-114.

13. Kokot, F. and Dulawa, J. (2000) Tamm-Horsfall protein updated. Nephron, $\mathbf{8 5}, 97-102$.

14. Mattey, M. and Naftalin, L. (1992) Mechanoelectrical transduction, ion movement and water stasis in uromodulin. Experientia, 48, 975-980.

15. Dulawa, J., Jann, K., Thomsen, M., Rambausek, M. and Ritz, E. (1988) Tamm-Horsfall glycoprotein interferes with bacterial adherence to human kidney cells. Eur. J. Clin. Invest., 18, 87-91.
16. Bingham, C., Bulman, M.P., Ellard, S., Allen, L.I., Lipkin, G.W., Hoff, W.G., Woolf, A.S., Rizzoni, G., Novelli, G., Nicholls, A.J. et al. (2001) Mutations in the hepatocyte nuclear factor-1beta gene are associated with familial hypoplastic glomerulocystic kidney disease. Am. J. Hum. Genet., 68, 219-224.

17. van Rooijen, J.J., Voskamp, A.F., Kamerling, J.P. and Vliegenthart, J.F. (1999) Glycosylation sites and site-specific glycosylation in human TammHorsfall glycoprotein. Glycobiology, 9, 21-30.

18. Fletcher, A.P., Neuberger, A. and Ratcliffe, W.A. (1970) Tamm-Horsfall urinary glycoprotein. The subunit structure. Biochem. J., 120, 425-432.

19. Serafini-Cessi, F., Malagolini, N., Hoops, T.C. and Rindler, M.J. (1993) Biosynthesis and oligosaccharide processing of human Tamm-Horsfall glycoprotein permanently expressed in HeLa cells. Biochem. Biophys. Res. Commun., 194, 784-790.

20. Bingham, C., Ellard, S., van't Hoff, W.G., Simmonds, H.A., Marinaki, A.M., Badman, M.K., Winocour, P.H., Stride, A., Lockwood, C.R., Nicholls, A.J. et al. (2003) Atypical familial juvenile hyperuricemic nephropathy associated with a hepatocyte nuclear factor-1beta gene mutation. Kidney Int., 63, 1645-1651.

21. Campbell, I.D. and Bork, P. (1993) Epidermal growth factor-like modules. Curr. Opin. Struct. Biol., 3, 385-392.

22. Jovine, L., Qi, H., Williams, Z., Litscher, E. and Wassarman, P.M. (2002) The ZP domain is a conserved module for polymerization of extracellular proteins. Nat. Cell Biol., 4, 457-461.

23. Wiggins, R.C. (1987) Uromucoid (Tamm-Horsfall glycoprotein) forms different polymeric arrangements on a filter surface under different physicochemical conditions. Clin. Chim. Acta, 162, 329-340.

24. Werner, J.M., Knott, V., Handford, P.A., Campbell, I.D. and Downing, A.K (2000) Backbone dynamics of a cbEGF domain pair in the presence of calcium. J. Mol. Biol., 296, 1065-1078.

25. Downing, A.K., Knott, V., Werner, J.M., Cardy, C.M., Campbell, I.D. and Handford, P.A. (1996) Solution structure of a pair of calcium-binding epidermal growth factor-like domains: implications for the Marfan syndrome and other genetic disorders. Cell, 85, 597-605.

26. Reinhardt, D.P., Ono, R.N. and Sakai, L.Y. (1997) Calcium stabilizes fibrillin-1 against proteolytic degradation. J. Biol. Chem., 272, 1231-1236.

27. Malagolini, N., Cavallone, D. and Serafini-Cessi, F. (1997) Intracellular transport, cell-surface exposure and release of recombinant Tamm-Horsfall glycoprotein. Kidney. Int., 52, 1340-1350.

28. Cavallone, D., Malagolini, N. and Serafini-Cessi, F. (2001) Mechanism of release of urinary Tamm-Horsfall glycoprotein from the kidney GPIanchored counterpart. Biochem. Biophys. Res. Commun., 280, 110-114.

29. Fukuoka, S. and Kobayashi, K. (2001) Analysis of the C-terminal structure of urinary Tamm-Horsfall protein reveals that the release of the glycosyl phosphatidylinositol-anchored counterpart from the kidney occurs by phenylalanine-specific proteolysis. Biochem. Biophys. Res. Commun., 289, $1044-1048$.

30. Schrijver, I., Liu, W., Brenn, T., Furthmayr, H. and Francke, U. (1999) Cysteine substitutions in epidermal growth factor-like domains of fibrillin-1: distinct effects on biochemical and clinical phenotypes. Am. J. Hum. Genet., 65, 1007-1020.

31. Rutishauser, J. and Spiess, M. (2002) Endoplasmic reticulum storage diseases. Swiss Med. Weekly, 132, 211-222.

32. Kaufman, R.J. (2002) Orchestrating the unfolded protein response in health and disease. J. Clin. Invest., 110, 1389-1398.

33. Tanaka, Y., Ueda, K., Ozawa, T., Sakuragawa, N., Yokota, S., Sato, R., Okamura, S., Morita, M. and Imanaka, T. (2002) Intracellular accumulation of antithrombin Morioka (C95R), a novel mutation causing type I antithrombin deficiency. J. Biol. Chem., 277, 51058-51067.

34. Whiteman, P. and Handford, P.A. (2003) Defective secretion of recombinant fragments of fibrillin-1: implications of protein misfolding for the pathogenesis of Marfan syndrome and related disorders. Hum. Mol. Genet., 12, 727-737.

35. Hoyer, J.R., Sisson, S.P. and Vernier, R.L. (1979) Tamm-Horsfall glycoprotein: ultrastructural immunoperoxidase localization in rat kidney. Lab. Invest., 41, 168-173.

36. Sikri, K.L., Foster, C.L., MacHugh, N. and Marshall, R.D. (1981) Localization of Tamm-Horsfall glycoprotein in the human kidney using immuno-fluorescence and immuno-electron microscopical techniques. J. Anat., 132, 597-605.

37. Reeves, W.B. and Molony, D.A. (1988) The physiology of loop diuretic action. Semin. Nephrol., 8, 225-233.

38. Ying, W.Z. and Sanders, P.W. (1998) Dietary salt regulates expression of Tamm-Horsfall glycoprotein in rats. Kidney Int., 54, 1150-1156. 
39. Leeker, A., Kreft, B., Sandmann, J., Bates, J., Wasenauer, G., Muller, H., Sack, K. and Kumar, S. (1997) Tamm-Horsfall protein inhibits binding of S- and P-fimbriated Escherichia coli to human renal tubular epithelial cells. Exp. Nephrol., 5, 38-46.

40. Kreft, B., Jabs, W.J., Laskay, T., Klinger, M., Solbach, W., Kumar, S. and van Zandbergen, G. (2002) Polarized expression of Tamm-Horsfall protein by renal tubular epithelial cells activates human granulocytes. Infect. Immun., 70, 2650-2656.

41. Mayrer, A.R., Kashgarian, M., Ruddle, N.H., Marier, R., Hodson, C.J., Richards, F.F. and Andriole, V.T. (1982) Tubulointerstitial nephritis and immunologic responses to Tamm-Horsfall protein in rabbits challenged with homologous urine or Tamm-Horsfall protein. J. Immunol., 128, 2634-2642.

42. Hoyer, J.R. (1980) Tubulointerstitial immune complex nephritis in rats immunized with Tamm-Horsfall protein. Kidney Int., 17, 284-292.

43. Zager, R.A., Cotran, R.S. and Hoyer, J.R. (1978) Pathologic localization of Tamm-Horsfall protein in interstitial deposits in renal disease. Lab. Invest., $38,52-57$.
44. Resnick, J.S., Sisson, S. and Vernier, R.L. (1978) Tamm-Horsfall protein. Abnormal localization in renal disease. Lab. Invest., 38, 550-555.

45. Chambers, R., Groufsky, A., Hunt, J.S., Lynn, K.L. and McGiven, A.R. (1986) Relationship of abnormal Tamm-Horsfall glycoprotein localization to renal morphology and function. Clin. Nephrol., 26, 21-26.

46. Emma, F., Muda, A.O., Rinaldi, S., Boldrini, R., Bosman, C. and Rizzoni, G. (2001) Acquired glomerulocystic kidney disease following hemolytic uremic syndrome. Pediatr. Nephrol., 16, 557-560.

47. Maesaka, J.K. and Fishbane, S. (1998) Regulation of renal urate excretion: a critical review. Am. J. Kidney Dis., 32, 917-933.

48. Leal-Pinto, E., Cohen, B.E., Lipkowitz, M.S. and Abramson, R.G. (2002) Functional analysis and molecular model of the human urate transporter/ channel, hUAT. Am. J. Physiol. Renal Physiol., 283, F150-163.

49. Enomoto, A., Kimura, H., Chairoungdua, A., Shigeta, Y., Jutabha, P., Cha, S.H., Hosoyamada, M., Takeda, M., Sekine, T., Igarashi, T. et al. (2002) Molecular identification of a renal urate anion exchanger that regulates blood urate levels. Nature, 417, 447-452. 